UNIVERSIDADE DE SÃO PAULO

FACULDADE DE FILOSOFIA, CIÊNCIAS E LETRAS DE RIBEIRÃO PRETO

DEPARTAMENTO DE PSICOLOGIA E EDUCAÇÃO

PROGRAMA DE PÓS-GRADUAÇÃO EM PSICOBIOLOGIA

\title{
COMPARAÇÕES DE TAMANHOS SOB INFORMAÇÕES PICTÓRICAS DE PROFUNDIDADE PROVENIENTES DE GRADIENTES DE TEXTURA E HORIZONTE EM EXPOSIÇÕES BREVES
}

Leonardo Gomes Bernardino

Dissertação de Mestrado apresentada à Faculdade de Filosofia, Ciências e Letras de Ribeirão Preto - USP, como parte das exigências para obtenção do título de Mestre. Área: Psicobiologia.

Ribeirão Preto

2008 
UNIVERSIDADE DE SÃO PAULO

FACULDADE DE FILOSOFIA, CIÊNCIAS E LETRAS DE RIBEIRÃO PRETO

DEPARTAMENTO DE PSICOLOGIA E EDUCAÇÃO

PROGRAMA DE PÓS-GRADUAÇÃO EM PSICOBIOLOGIA

\title{
COMPARAÇÕES DE TAMANHOS SOB INFORMAÇÕES PICTÓRICAS DE PROFUNDIDADE PROVENIENTES DE GRADIENTES DE TEXTURA E HORIZONTE EM EXPOSIÇÕES BREVES
}

\author{
Leonardo Gomes Bernardino \\ Orientador: Sérgio Sheiji Fukusima \\ Dissertação de Mestrado apresentada à Faculdade de \\ Filosofia, Ciências e Letras de Ribeirão Preto - USP, \\ como parte das exigências para obtenção do título de \\ Mestre. Área: Psicobiologia.
}

Ribeirão Preto

2008 
Autorizo a reprodução e/ou divulgação total ou parcial da presente obra, por qualquer meio convencional ou eletrônico, desde que citada a fonte.

\section{Ficha Catalográfica}

Bernardino, Leonardo Gomes

Comparações de tamanhos sob informações pictóricas de profundidade provenientes de gradientes de textura e horizonte em exposições breves. Ribeirão Preto, 2008. 66 p.: il.; $30 \mathrm{~cm}$.

Dissertação apresentada à Faculdade de Filosofia, Ciências e Letras de Ribeirão Preto/USP - Departamento de Psicologia e Educação. Área de concentração: Psicobiologia.

Orientador: Prof. Dr. Sérgio Sheiji Fukusima

1. Percepção de tamanho

2. Informações pictóricas de profundidade

3. Exposição breve 


\section{FOLHA DE APROVAÇÃO}

Leonardo Gomes Bernardino

Comparações de tamanhos sob informações pictóricas de profundidade provenientes de gradientes de textura e horizonte em exposições breves.

Dissertação apresentada à Faculdade de Filosofia, Ciências e Letras de Ribeirão Preto - USP, como parte das exigências para obtenção do título de Mestre. Área: Psicobiologia.

Aprovado em:

Banca Examinadora

Prof. Dr. Sérgio Sheiji Fukusima (Orientador)

Instituição: FFCLRP - Universidade de São Paulo. Assinatura:

Prof. Dr. César Alexis Galera

Instituição: FFCLRP - Universidade de São Paulo. Assinatura:

Prof. Dr. Joaquim Carlos Rossini

Instituição: IP - Universidade Federal de Uberlândia. Assinatura: 
Para Vilmar e Irinéa, com todo o meu amor e carinho. 


\section{AGRADECIMENTOS}

A Deus pelo dom da vida e a Virgem Maria por ter me preservado nessa caminhada.

Ao meu orientador Prof. Sérgio Sheiji Fukusima pelos ensinamentos, paciência e incentivo a sempre estudar mais.

Aos professores César Alexis Galera, meu assessor nesses dois anos, e Joaquim Carlos Rossini, que leu uma versão preliminar desta dissertação, pelas sugestões e observações valiosas.

Aos colegas do laboratório de Percepção e Psicofísica, Nelson, Ana Irene, Luciana, Kátia Maria, Amélia, Adriana, Lina, Patrícia, Kátia e Cínthia, pelos momentos sérios e de descontração.

Ao Igor, técnico do laboratório, pela assessoria nos assuntos referentes à tecnologia.

As secretárias Renata Vicentini, Regina Teles e Maria Inês Joaquim, pela disposição em atender minhas solicitações na pós-graduação.

Ao Bruno, um irmão, que me tolera no laboratório e em casa, pelo convívio divertido e as discussões teóricas e filosóficas (dá zero pra ele!).

A Larissa, mais que irmã, amiga e confidente, pela companhia e cuidado em todos os momentos.

Ao João Vítor, que ainda nem pode ler este agradecimento, mas faz minha vida ser melhor.

A Morgana, companheira inigualável nesses quase dois anos, pela paciência, compreensão e apoio incondicionais.

Aos amigos de pós-graduação Lucas (sempre com meias bonitas), Felipe (futebol é memória), Milena (nunca vacila), Mikael (discussões no corredor) e Roberto e Édson (cafezinho depois do almoço). 
Aos grandes amigos Mestre (revelando e cobrando em sua máquina quente), Dudu (o ponto final de todas as discussões) e Laranja (evitando a fadiga).

Aos primos, Ita, Raoni e Vinícius, pelas conversas e viagens, momentos singulares.

Aos corajosos psicólogos, ou quase, Pablo, Kagimura, Rômulo, Reginaldo, Matheus, João, Renato, Diego e Arthur pelo apoio.

As amigas, Sol, Jesse, Thê, Carol, Neném e Luciane, por tornarem as idas para Uberlândia sempre mais agradáveis.

Aos meus familiares, avós, tios e primos, que mesmo não entendendo a natureza de meu trabalho sempre torceram e rezaram de longe.

Ao CNPq, pela bolsa concedida. 
'Eu quase que nada não sei, mas desconfio de muita coisa.

João Guimarães Rosa 


\section{RESUMO}

Bernardino, L. G. Comparações de tamanhos sob informações pictóricas de profundidade provenientes de gradientes de textura e horizonte em exposições breves. 2008. 66 f. Dissertação (Mestrado) - Faculdade de Filosofia, Ciências e Letras de Ribeirão Preto, Universidade de São Paulo, Ribeirão Preto-SP, 2008.

Teve-se por objetivo investigar se o tempo de exposição das informações de profundidade afeta a comparação de tamanho de objetos pictóricos. Para isso, 120 participantes distribuídos aleatoriamente em 12 grupos julgaram qual de duas barras verticais, uma a teste e outra a padrão, era maior. Usando o método dos estímulos constantes, estas barras podiam ser apresentadas simultaneamente por $50 \mathrm{~ms}, 100 \mathrm{~ms}$ ou $200 \mathrm{~ms}$ em quatro condições de fundo de tela: (1) sem textura, (2) com apenas a linha do horizonte, (3) com o horizonte e o gradiente de linhas de compressão, e (4) com o horizonte e o gradiente de linhas de perspectiva. A inclinação das curvas psicométricas, os pontos de igualdade subjetiva (PIS) e o erro relativo foram calculados. A análise dos erros relativos indicou uma diferença significativa entre o gradiente de perspectiva e outras duas condições (controle e horizonte). Embora os tempos de exposição não tenham apresentado diferenças significativas entre si, observou-se uma maior superestimação do tamanho com apresentações de 100ms nas condições com indícios de profundidade (perspectiva e compressão). A análise das inclinações das curvas psicométricas mostrou uma maior sensibilidade dos participantes para efetuarem as comparações sob um tempo de $200 \mathrm{~ms}$ em relação ao de $50 \mathrm{~ms}$, independentemente do fundo de tela. Os erros relativos maiores para a condição com linhas de perspectiva confirmam evidências de que esta é uma informação de profundidade eficiente na modulação do tamanho percebido. Além disso, é possível que essa eficiência seja maximizada nas condições em que os estímulos são expostos em torno dos 100ms.

Palavras-chave: percepção de tamanho; informações pictóricas de profundidade; exposição breve. 


\begin{abstract}
Bernardino, L. G. Size comparisons under effects of pictorial depth cues from texture gradient and horizon in brief exposures. 2008. 66 f. Dissertação (Mestrado) - Faculdade de Filosofia, Ciências e Letras de Ribeirão Preto, Universidade de São Paulo, Ribeirão Preto-SP, 2008.

The aim of this study was to investigate the effects of the duration of pictorial depth cue exposures on perceived sizes of stimuli. For this, 120 volunteers distributed randomly in 12 groups compared two vertical bars, one the test and other the standard, in to order to report which one was bigger. Using the method of constant stimuli, these bars could be presented simultaneously for 50,100 or 200ms in four background conditions: (1) without depth cues, (2) with only the horizon, (3) with the horizon and compression line gradient, and (4) with the horizon and perspective line gradient. The slope of the psychometric curves, the points of subjectivity equality (PSE) and relative errors were calculated. The analysis of relative errors indicated a significant difference among the perspective gradient and other two conditions (without texture and horizon). Although exposure time had not presented significant differences among them, it was observed size overestimation during the $100 \mathrm{~ms}$ exposure in depth cues conditions (compression and perspective). The analysis of slope's psychometric function showed a greater sensibility in the participants who made comparisons with $200 \mathrm{~ms}$ than the ones who made with 50ms, independently of depth cue background. Pronounced relative errors in comparisons with perspective gradient tend to agree with previous studies, which demonstrate higher influence of this cue in perceived size modulation. Besides, this efficiency seems to be maximized when stimuli exposure time was $100 \mathrm{~ms}$.
\end{abstract}

Keywords: size perception; depth cues; brief exposure. 


\section{LISTA DE ILUSTRAÇÕES}

Figura 1. Representação de diferentes inclinações da curva psicométrica. Quanto maior for a inclinação desta, maior a sensibilidade do sistema sensorial para identificar alterações no nível de estimulação.

Figura 2. Exemplos dos fundos de tela utilizados no experimento: sem textura (a), com a linha do horizonte (b), com o gradiente de textura formado por linhas de compressão (c) e com o gradiente de textura formado por linhas de perspectiva (d) Nesses exemplos, em todas as situações ambas as barras possuem o mesmo tamanho, que na imagem original é de 100 pixels. .32

Figura 3. Esquema de apresentação de estímulos no experimento para cada tentativa .35

Figura 4. Médias (valores modulares) e erros padrões dos erros relativos para as comparações de tamanho realizadas com o estímulo teste embaixo do estímulo padrão. 39

Figura 5. Médias e erros padrões dos erros relativos para as comparações de tamanho realizadas com o estímulo teste acima do estímulo padrão. 42

Figura 6. Curvas psicométricas, nas quais se observam suas inclinações, para as comparações de tamanho realizadas ora com o estímulo teste acima do estímulo padrão (coluna esquerda) ora com o estímulo teste abaixo do estímulo padrão (coluna direita). Desse modo, há diferentes resultados dispostos para as comparações realizadas nos quatro fundos de telas: sem textura (a e b), com linha do horizonte (c e d), com gradiente de compressão (e e f) e com gradiente de perspectiva ( $g$ e h) 


\section{SUMÁRIO}

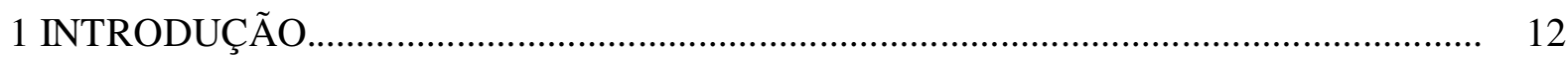

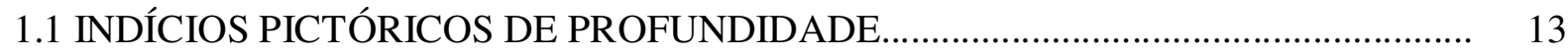

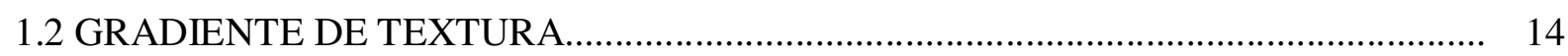

1.3 HIPÓTESE DA RELAÇÃO TAMANHO-DISTÂNCIA................................................ 19

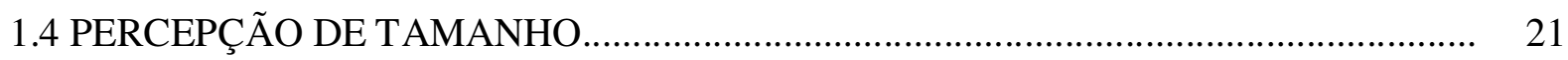

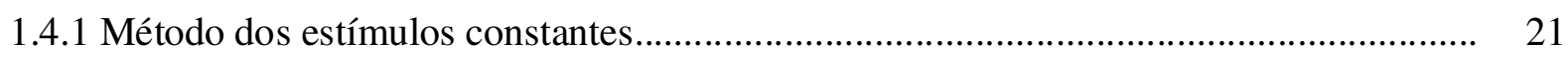

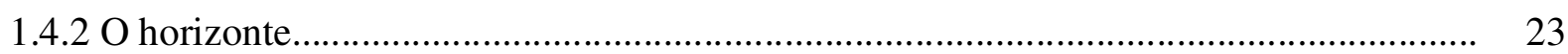

1.4.3 Outros fatores moduladores do tamanho percebido.................................................... 26

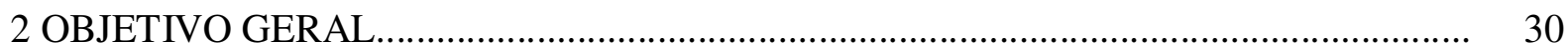

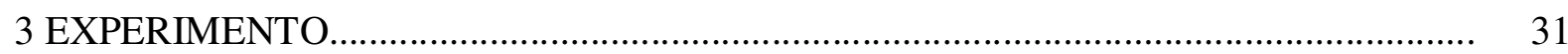

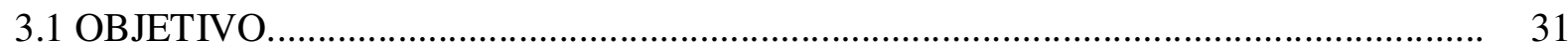

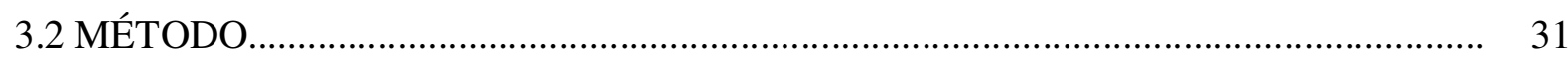

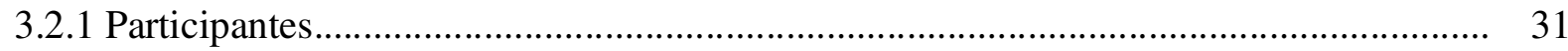

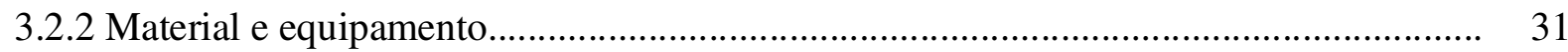

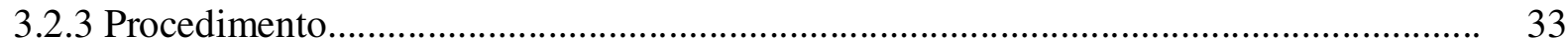

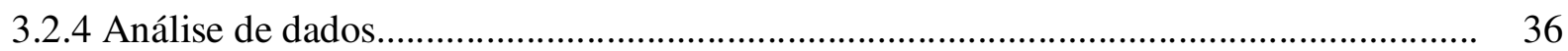

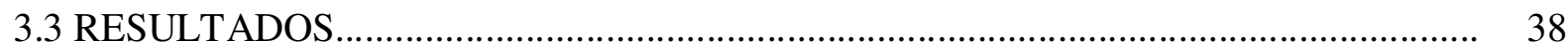

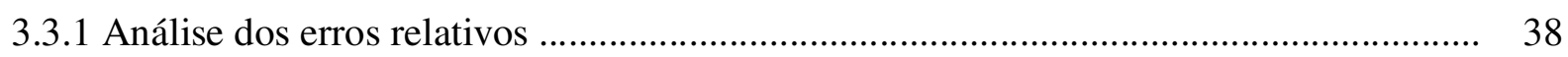

3.3.2 Análise das inclinações das curvas psicométricas...................................................... 43

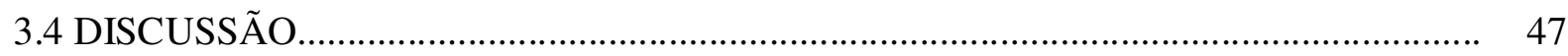

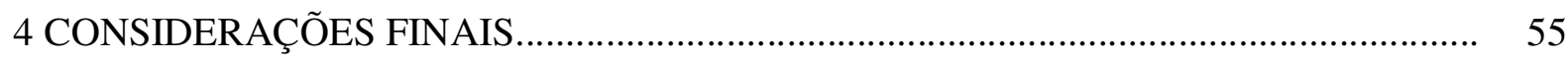

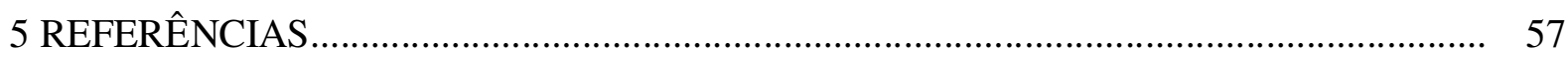

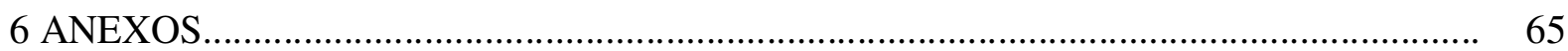

ANEXO A - Termo de Consentimento Livre e Esclarecido.................................................. 66

ANEXO B - Aprovação do Comitê de Ética da FFCLRP - USP............................................ 67 


\section{INTRODUÇÃO}

O sistema visual humano codifica a informação luminosa em sinais químicos e elétricos, os quais são enviados ao sistema nervoso central, onde são ordenados, processados e interpretados. Várias estruturas cerebrais - desde níveis simples até outros de alta complexidade estão envolvidas em processos seqüenciais e reverberantes, através dos quais interagimos com o ambiente, tomamos decisões, planejamos e executamos ações. É todo esse processamento que nos possibilita realizar tarefas como estimar a distância e o tamanho de objetos.

O tamanho dos objetos e a distância - egocêntrica (distância entre observador e um objeto) e exocêntrica (distância entre objetos) - são informações muito importantes para nos relacionarmos com o ambiente de maneira satisfatória. Durante todo o tempo realizamos estimativas de tamanho e distância dos objetos com os quais interagimos, o que é fundamental para nos situarmos e locomover-nos nos espaços em que nos encontramos. Gibson (1970) afirma que a percepção visual do espaço evoluiu na espécie humana em resposta às demandas ambientais, garantindo maior sobrevivência aos nossos ancestrais.

Uma questão intrigante é como se dá a percepção de um ambiente estável em três dimensões, se o nosso sistema óptico está organizado em estruturas bidimensionais. Isso é possível graças à utilização de informações presentes no ambiente, os chamados indícios de profundidade. 


\subsection{INDÍCIOS PICTÓRICOS DE PROFUNDIDADE}

Essas informações são acessíveis tanto por apenas um olho, os indícios monoculares, como pela ação conjunta de ambos os olhos, os indícios binoculares. Sternberg (2000) aponta dois sinais binoculares: a convergência e a disparidade binocular. E entre os sinais monoculares cita: a interposição, a perspectiva aérea ou nitidez, a perspectiva linear, o gradiente de textura, o tamanho relativo, a localização no plano pictórico e a paralaxe do movimento.

A orientação sobre a superfície é estimada primeiramente de forma independente, a partir de indícios de profundidade individuais monoculares e binoculares, e depois essas informações são integradas para construir uma representação geral de superfícies em espaço tridimensional.

A utilização destas dicas provavelmente conferiu vantagens reprodutivas e de sobrevivência para as espécies que necessitam representar o espaço. Cada espécie vai se beneficiar diferentemente das mesmas dicas de acordo com a demanda ambiental. Entretanto, é preciso ter em vista que nossa percepção de profundidade não é exclusiva no reino animal. Pelo contrário, ela é homóloga à de outros animais, como os primatas - Rhesus e baboons estão sujeitos às mesmas ilusões visuais do que os humanos (BARBET; FAGOT, 2002) - e as aves - os pombos são sensíveis às mesmas informações de distância monoculares do que os humanos (CAVOTO; COOK, 2006) - só para ficar em dois exemplos.

A partir da década de 90 do século passado, vários estudos foram realizados com o intuito de investigar como ocorre a integração das diferentes dicas para a percepção de distância, o que gerou hipóteses para explicá-la (GEISLER; KERSTEN, 2002; HARWERTH; MOELLER; WENSVEEN, 1998; HILLIS et al., 2004; JACOBS, 1999, 2002; KNILL; SAUNDERS, 2003; LANDY et al., 1995; ORUÇ; MALONEY; LANDY, 2003; POOM; BORJESSON, 1999; TSUTSUI et al., 2001; YOUNG; LANDY; MALONEY, 1993). 
A partir desses trabalhos, depreende-se um consenso de que o sistema visual combina os indícios de acordo com sua confiabilidade, dando-lhes pesos para gerar a percepção da profundidade. Estes pesos são proporcionais à qualidade da informação e são continuamente alterados, de acordo com a necessidade. Desse modo, o sistema visual faz uso dos indícios mais confiáveis e combina-os, seguindo uma estrutura ótima, de acordo com uma estatística bayesiana, para construir a melhor representação possível do espaço tridimensional.

O conhecimento sobre a integração das dicas pictóricas recebeu muitos aportes nos últimos anos. A despeito disso, o efeito que cada uma das diferentes informações tem, separadamente, sobre a percepção de profundidade, não está completamente elucidado. É por essa razão, dentre outras, que se justifica o experimento apresentado nesta dissertação: estender a compreensão de como o gradiente de textura e o horizonte afetam a percepção de tamanho e distância.

\subsection{GRADIENTE DE TEXTURA}

Segundo Schiffman (2005), o gradiente de textura pode ser entendido como uma informação pictórica de profundidade, na qual à medida que aumenta a distância para o observador, os elementos constituintes da superfície parecem menores e projetam texturas mais finas ou densas. Para Gibson (1979), o gradiente de textura seria fundamental e uma condição suficiente para a percepção da profundidade.

Confirmando essa idéia, Sinai, Ooi e He (1998) encontraram que, quando há informação sobre a textura da superfície disponível, a percepção de distância absoluta é bastante acurada. Desse modo, as informações contidas nos gradientes de textura têm um papel fundamental no 
cálculo da distância. Por correlacionar-se tão bem com a distância, a densidade da textura sobre a retina também forneceria um padrão para a estimativa do tamanho dos objetos.

Mais recentemente, em uma revisão bibliográfica sobre a percepção visual do espaço publicada por Da Silva et al. (2006), o gradiente de textura é indicado como provedor de informações de profundidade, caso não envolva movimento, e de distância relativa. Parece não haver dúvidas quanto à repercussão do gradiente de textura sobre a percepção espacial de três dimensões.

A descrição apresentada acima de Schiffman (2005), embora seja bastante útil em textos e livros básicos para que iniciantes nessa área do saber compreendam o conceito, é muita ampla e de difícil operacionalização. Stevens (1984) já havia alertado para esse problema. Uma conceituação mais objetiva é encontrada no trabalho de Hillis et al. (2004), que expõem que a informação contida no gradiente de textura pode ser decomposta em três: scaling (escalonamento), foreshortening (compressão) e density (densidade). O escalonamento é a mudança no tamanho projetado dos elementos de textura, a compressão consiste em alterações na forma projetada destes elementos e a densidade é a mudança no número de elementos por unidade de área.

Assim, as superfícies contêm informações distintas de gradiente de textura, que servem como dicas de profundidade para a percepção do espaço. Um dos primeiros trabalhos que abarcaram esses elementos foi o de Cutting e Millard (1984). Eles estudaram três gradientes de textura (perspectiva, compressão e densidade) na impressão de superfícies planas e curvas. Os resultados indicaram que os gradientes mais importantes para o julgamento de distância na superfície plana foram o de perspectiva e o de densidade.

Mais de uma década depois, Goodenough e Gilliam (1997) avançaram na idéia de que o gradiente de compressão tem pequena influência na percepção da profundidade. Esses autores 
formularam a hipótese de que não há uma estrutura diferenciada para a detecção direta deste gradiente e, por isso, ele não seria computado de maneira rápida. Outros autores também mostraram que a perspectiva seria o principal determinante para a percepção da inclinação, esta um indicativo de profundidade para o sistema visual (ALLISON; HOWARD, 2000). A prevalência da perspectiva ocorreria mesmo na presença de outras informações de textura (SAUNDERS; BACKUS, 2006), e ela seria uma dica suficiente para a localização de um objeto no solo, sendo as informações binoculares redundantes para tal tarefa (LOOMIS; PHILBECK; ZAHORIK, 2002).

Um trabalho recente que investiga os efeitos de dicas pictóricas sobre a percepção de profundidade é o de $\mathrm{Wu}, \mathrm{He}$ e Ooi (2007). Estes autores empreenderam 7 (sete) experimentos, com tarefas de estimar a distância absoluta, para verificar como a perspectiva linear age para a construção de uma representação da superfície. Os resultados indicaram que na presença da perspectiva a distância julgada é superestimada, confirmando que esse gradiente fornece uma importante informação de profundidade e, por isso, influencia fortemente as estimativas de distância.

Essa influência é tão marcante que independe de como a informação de perspectiva é formada (se por pontos ou linhas), do número de elementos que a constituem (apenas quatro elementos são suficientes) e do tipo de tarefa para fornecer as estimativas (relato verbal ou lançamento às cegas). Além disso, os resultados de Wu, He e Ooi (2007) apontaram que não há diferença significativa entre os julgamentos de distância, sejam eles feitos sob o gradiente de compressão ou sob pontos ou linhas igualmente espaçados (situação controle). O desempenho no julgamento de distância em tais condições foi pior do que os realizados sob o gradiente de perspectiva. 
Estes achados se coadunam com os de Cutting e Millard (1984) e Goodenough e Gilliam (1997), em suas observações de que o sistema visual teria uma menor sensibilidade para detectar alterações no gradiente de compressão em comparação com o gradiente de perspectiva. Em conjunto, essas são fortes evidências de quão eficiente é o sistema visual para extrair as informações de profundidade contidas na perspectiva linear.

Diferentemente desses estudos, algumas pesquisas não acharam diferenças significativas entre a influência que os gradientes de perspectiva e compressão exercem sobre julgamentos de distância (O’BRIEN; JOHNSTON, 2000) e outros até acharam efeitos contrários, isto é, o gradiente de compressão forneceria dicas mais confiáveis de profundidade do que a perspectiva em grandes inclinações (ANDERSEN; BRAUNSTEIN; SAIDPOUR, 1998).

Em um estudo recente, Lappin, Shelton e Rieser (2006) pediram aos participantes que indicassem o ponto médio entre si e outra pessoa (tarefa de bissecção) em três diferentes contextos reais. O desempenho foi pior (baixa precisão e confiança no julgamento) no contexto com muitas informações de perspectiva linear. Os autores inferiram então, que a perspectiva contribuiria pouco para a percepção de distância. Entretanto é mais provável que tal resultado tenha ocorrido devido à largura estreita do ambiente em questão, o que reduziria o campo visual, dificultando o julgamento.

Não se deve negligenciar que esses resultados contraditórios são decorrentes de diferenças experimentais, as quais já foram relatadas no supracitado trabalho de Cutting e Millard (1984). Eles encontraram uma maior efetividade do gradiente de compressão para fornecer informação de distância em superfícies curvas. Assim, não se pode afirmar categoricamente qual tipo de gradiente é mais efetivo para fornecer informações de profundidade. Tal afirmação só pode ser feita se dados adicionais, como o tipo de superfície e o método utilizado forem descritos. 
As áreas cerebrais envolvidas no processamento dos indícios de profundidade têm sido estudadas através de técnicas de mapeamento cerebral. Os trabalhos de Sakata, Tsutsui e Taira (2005) e Tsutsui et al. (2001, 2002, 2005) mostraram que os neurônios situados na área intraparietal caudal e à sua volta estão envolvidos no processamento de alta ordem, integrando informações de diferentes fontes para a construção de uma representação tridimensional dos objetos. Assim, haveria neurônios de orientação de superfície nesta área, que responderiam seletivamente ao gradiente de textura e à perspectiva linear.

Uma discussão existente nesses estudos neurofisiológicos diz respeito à via - dorsal ou ventral - onde ocorreria o processamento das informações de perspectiva. Enquanto alguns defendem a via dorsal (WELCHMAN et al., 2005), outros argumentam pela via ventral (BRUGGEMANN; YONAS; KONCZAK, 2007). Contudo, é mais razoável pensar em um processamento paralelo das informações, assim a divisão entre as vias não seria tão rigorosa. Além disso, outras áreas parecem estar implicadas na percepção de profundidade, como os gânglios basais e o cerebelo (MASCHKE et al, 2006).

Feita essa exposição sobre a percepção de distância, deve-se lembrar de sua relação com a percepção de tamanho. A imagem retiniana, que é a base para a apreensão do tamanho de um objeto, é inversamente proporcional à distância do objeto. Portanto, quanto mais longe um objeto estiver, menor será a projeção deste na retina e, conseqüentemente, o seu tamanho.

Contudo, essa relação não é tão direta e inequívoca como pode parecer. Foley, RibeiroFilho e Da Silva (2004) indicaram que o tamanho percebido muda menos que o tamanho da imagem à medida que a distância aumenta. Assim, a possível existência de uma relação entre o tamanho e a distância é a discussão que empreendemos a seguir. 


\subsection{HIPÓTESE DA RELAÇÃO TAMANHO-DISTÂNCIA}

As investigações sobre a influência da percepção de tamanho sobre a percepção de distância, e vice-versa, são muito antigas e remontam à primeira metade do século passado. Um trabalho que fornece um excelente panorama sobre esse assunto é o de Epstein, Park e Casey (1961). A partir de uma revisão bibliográfica, os autores compilaram três hipóteses explicativas sobre a relação entre a percepção de tamanho e de distância: a hipótese da invariância tamanhodistância (HITD), a hipótese do tamanho conhecido-distância aparente e a lei de Emmert.

Dentre estas hipóteses a mais aceita, porém longe de ser consenso, é a da invariância tamanho-distância (HITD). Essa postula que o tamanho é determinado pela interação entre as informações de distância e o ângulo visual projetado na retina. Um estudo clássico que respalda essa hipótese é o de Holway e Boring (1941), segundo o qual a percepção de tamanho é regida por duas regras.

A primeira é a de que o tamanho seria indicado pela extensão da imagem dos objetos projetados na retina, isto é, por meio de uma estimativa do tamanho do ângulo visual. A segunda regra refere-se à constância de tamanho, que é a tendência de estimar o tamanho dos objetos invariante do tamanho de sua imagem retiniana, sendo esta inversamente proporcional à distância

entre o objeto e o observador. Dependendo das circunstâncias em que os objetos são percebidos, a primeira ou a segunda regra é mais preponderante para determinar a percepção de tamanho.

Os mesmos autores encontraram que ambas as regras estão intrinsecamente ligadas com as informações de distância dos objetos. Assim, à medida que as informações sobre a distância eram progressivamente reduzidas, o tamanho julgado se afastava cada vez mais do tamanho objetivo em direção às expectativas das imagens retinianas. Tais evidências demonstraram que a percepção de tamanho e a percepção de distância estão relacionadas. 
Argumentos pró e contra a hipótese de HITD têm sido apresentados em pesquisas recentes, como as de Imamura e Nakamizo (2006), Kauffman et al. (2007), Haber e Levin (2001) e Tozawa e Oyama (2006). Dentre os estudos que defendem a pertinência da HITD, pode-se citar o de Imamura e Nakamizo (2006), os quais investigaram e comprovaram a hipótese de que a lei de Emmert seria um caso especial da HITD; e o de Kaufman et al. (2007), que encontraram suporte para a HITD ao investigarem a ilusão da lua, fenômeno no qual a lua próxima ao horizonte parece bem maior do que quando localizada no zênite.

Com resultados semelhantes, Haber e Levin (2001) e Tozawa e Oyama (2006) utilizaramse dos mesmos argumentos para, respectivamente, atacar e defender a HITD. Os primeiros sugerem que não há diferença significativa em estimar o tamanho de objetos comuns, seja pela memória ou pela visão propriamente dita. Defendem, assim, que até a nomenclatura dada (percepção) estaria incorreta, pois outros processos cognitivos, nesse caso a memória, descrita em termos de familiaridade, seria o fator determinante no julgamento de tamanho.

Por outro lado, Tozawa e Oyama (2006) afirmam que seus resultados são consistentes com a HITD, a despeito de encontrarem que o sistema visual computa o tamanho e a distância independentemente, utilizando-se das dicas mais confiáveis de acordo com a situação. Assim, mostram que a relação entre tamanho e distância não é facilmente explicada em termos de percepto-percepto, isto é, não é uma relação direta e inequívoca.

Um argumento que ajuda a esclarecer a relação entre tamanho e distância é a apresentada por O’Brien (1997, apud O’BRIEN; JOHNSTON, 2000). Para este autor, se os julgamentos forem efetuados sem limitações visuais, os processamentos de tamanho e de distância não seriam relacionados. Por outro lado, se existissem limitações, o sistema visual necessitaria de uma mediação cognitiva, valendo-se da relação entre tamanho e distância, para forjar uma percepção mais acurada do espaço. 
Desse modo, uma posição que é cada vez mais aceita é a de que a percepção de distância egocêntrica é um processo independente da percepção de tamanho, porém o contrário não pode ser afirmado, já que a percepção de tamanho requer o conhecimento sobre a distância percebida do objeto (DA SILVA et al., 2006).

Como se pode notar, a relação entre tamanho e distância ainda é controversa, a despeito de muitos pesquisadores a terem investigado. Além disso, Hershenson (1999, apud HABER; LEVIN, 2001) afirma que estudos sobre a percepção de tamanho nunca receberam tanta atenção quanto os estudos sobre a percepção de profundidade e distância, o que suscita muitas perguntas ainda sem respostas.

\subsection{PERCEPÇÃO DE TAMANHO}

\subsubsection{Método dos estímulos constantes}

Um método psicofísico utilizado em investigações sobre o tamanho visualmente percebido é o dos estímulos constantes. Gescheider (1997) explica que nesse método, estímulos de comparação (estímulos teste) com valores acima e abaixo do estímulo padrão, de valor fixo, são apresentados aos participantes. A tarefa consiste em julgar se o estímulo teste é maior ou menor do que o padrão.

Ainda segundo Gescheider (1997), no método dos estímulos constantes, cada estímulo teste é apresentado repetidas vezes (no mínimo 20 vezes) de forma aleatória, o que permite a obtenção da proporção de respostas em que o estímulo teste é indicado como maior que o estímulo padrão. Essas proporções são então ajustadas a algum tipo de ogiva (cumulativa, 
logística ou outra), gerando uma curva psicométrica e permitindo o cálculo de constantes estatísticas como limiar, medida de precisão ou ponto de igualdade subjetiva.

Nas últimas décadas, o método dos estímulos constantes tem sido severamente criticado pelos defensores dos métodos adaptativos, como o das escadas duplas (CORNSWEET, 1962). Nesses métodos, a intensidade do estímulo a ser apresentado não é predeterminada, pois depende das respostas emitidas nas tentativas prévias. Desse modo, sua eficiência seria maior, porque concentra as tentativas próximas ao parâmetro a ser calculado, evitando tentativas distantes desse, que fornecem pouca informação útil (DAI, 1995; ERLEBACHER; SEKULER, 1971; LEVINSON; RESTLE, 1968; MASIN, 1987; WATSON; FITZHUGH, 1990).

Apesar das críticas contundentes sobre sua eficácia, o método dos estímulos constantes é ainda muito utilizado e foi escolhido por ter importantes pontos positivos: menor número de erros, menor variabilidade nos parâmetros calculados, simplicidade para implementá-lo, não necessita de hipóteses prévias sobre a forma da curva psicométrica e os resultados podem ser ajustados a várias funções. Estas vantagens foram expostas por Simpson (1988), que comparou através de simulações os métodos adaptativos e os não-adaptativos, fornecendo um parecer favorável ao uso do método dos estímulos constantes (não-adptativo).

Outra vantagem do método dos estímulos constantes é a possibilidade de avaliar a inclinação da curva psicométrica. Isso é possível, porque todos os pontos da curva são calculados, diferentemente dos métodos adaptativos que se atêm a apenas um ponto específico da curva. A medida da inclinação fornece-nos indícios sobre a sensibilidade do sistema visual para realizar determinada tarefa (CAMERON; TAI; CARRASCO, 2002). Desse modo, a inclinação informa sobre a alteração do desempenho dos observadores causada pela intensidade dos estímulos (KING-SMITH; ROSE, 1997). 
Na Figura 1 apresentam-se duas curvas psicométricas. Nota-se que a curva composta por linhas tracejadas é mais inclinada do que a formada por uma linha contínua. Isso indica um aumento na capacidade do sistema sensorial em responder às variações da estimulação física para os julgamentos dispostos na curva psicométrica com linhas tracejadas.

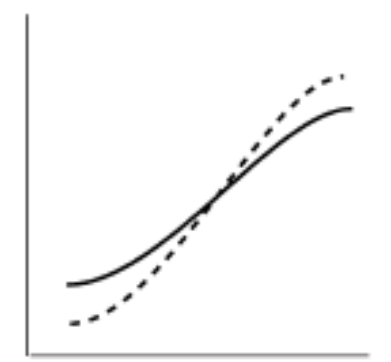

Figura 1: Exemplo de duas curvas psicométricas com diferentes inclinações. (Adaptado de Cameron, Tai \& Carrasco, 2002).

\subsubsection{O horizonte}

O efeito do horizonte é um dos principais aspectos investigados sobre a percepção de tamanho. Rogers (1996, p.142) define o horizonte como "o limite infinitamente distante de um plano na superfície"; ele é uma característica do arranjo óptico, não do ambiente, e sua posição localiza-se na altura dos olhos.

Embora Sedgwick (1980) tenha sido o primeiro a indicar que o horizonte afeta a percepção de tamanho independentemente da distância, o trabalho de Rogers (1996) é primordial para compreender essa influência. A partir dos resultados de três experimentos, a autora concluiu que o horizonte é uma poderosa informação para a estimativa do tamanho relativo, desde que a distância entre os estímulos a serem comparados não seja muito grande (no experimento 1) e que o horizonte não seja muito alto e nem muito baixo na figura (no experimento 2). 
O achado mais interessante, todavia, advém do experimento 3, no qual o horizonte estava ausente e, assim como nos outros dois experimentos, o participante ajustava o tamanho de um ponto para que este adquirisse o mesmo tamanho de uma barra padrão. Os resultados foram similares aos obtidos na presença do horizonte, sugerindo que os participantes continuaram valendo-se da informação fornecida pelo horizonte mesmo na ausência deste. A hipótese levantada é a de que o horizonte reflita a altura do nível dos olhos, ou seja, os participantes “impuseram" o nível dos olhos como horizonte.

No estudo de Bertamini, Yang e Proffitt (1998) obtiveram-se achados semelhantes e os dados ainda indicaram que o julgamento do tamanho relativo é mais acurado quanto mais próximo do horizonte estiver o estímulo. É importante ressaltar que em todos os experimentos por eles realizados, a linha do horizonte não era diretamente apresentada, sempre era implícita. Isto corrobora a hipótese de que a informação do horizonte pode ser acessada através do nível dos olhos do observador e é essencial para a percepção de tamanho relativo.

Do mesmo modo, o horizonte também influencia e é utilizado no julgamento de tamanho absoluto, confirmando que a percepção de distância independente deste (BERTAMINI; YANG; PROFFITT, 1998; BINGHAM, 1993; WRAGA, 1999). Apesar de reafirmarem essa independência, Bennett e Warren (2002) mostraram que informações de profundidade também podem ser acessadas a partir do horizonte. A distância de um objeto na superfície, sendo esta assumida como plana, poderia ser calculada pelo ângulo visual entre o ponto em que se encontra o objeto e o horizonte.

Outra relevante questão é a de que o horizonte é mais efetivo no auxílio à percepção de tamanho em ambientes imersivos (virtuais com o uso do head-mounted display, ou no mundo real propriamente dito) do que em ambientes não-imersivos, nos quais o centro da projeção seria indeterminado (DIXON et al., 2000). 
Recentemente, Alves e Fukusima (2005) encontraram que a presença do horizonte resultou em amplificação do tamanho percebido de objetos próximos a ele em relação a objetos afastados dele no hemicampo visual inferior. No artigo em questão, também foi investigada a possível interação entre o horizonte e o gradiente de textura. Caso esta existisse, o horizonte na representação pictórica seria percebido como tal e não apenas como a borda do gradiente de textura. Os resultados mostraram que a reprodução do espaço foi percebida como semelhante ao real, o que indica a existência da interação, sendo esta responsável pelo melhor desempenho dos participantes em comparar tamanhos de objetos próximos ao horizonte.

Em dois trabalhos mais recentes Ozkan e Braunstein (2006, 2007) também encontraram uma superestimação do tamanho de objetos localizados no horizonte. Em seus experimentos, a posição relativa ao horizonte de duas elipses era manipulada, enquanto o tamanho dos estímulos era igual e constante. Em conformidade com a HITD, o estímulo localizado mais acima em relação a outro no campo visual foi julgado maior e mais distante em duas condições: ambos os estímulos abaixo do horizonte ou um interceptando o horizonte e o outro abaixo deste.

Diferentemente, na condição em que ambos os estímulos eram posicionados acima do horizonte, aquele localizado mais acima no campo visual foi julgado menor e mais distante, configurando um exemplo do paradoxo tamanho-distância. É importante assinalar que este paradoxo é encontrado em julgamentos feitos através de relatos verbais, que acrescentam o componente cognitivo, e não nos baseados em ação, cuja influência da informação sensorial não é reduzida (MON-WILLIAMS; TRESILIAN, 1999).

Esses resultados corroboram as evidências anteriores e dão suporte consistente ao argumento de que o julgamento de tamanho relativo em arranjos tridimensionais, sejam eles formados por linhas desenhadas ou por fotografias de ambientes reais, é dependente da posição dos estímulos em relação ao horizonte. 


\subsubsection{Outros fatores moduladores do tamanho percebido}

Além do horizonte, exposto na seção anterior, as informações de profundidade provenientes de gradiente de textura são importantes moduladoras do tamanho visualmente percebido. Em trabalho publicado em 1996, William e Enns concluem que as distorções de tamanho na ilusão horizontal e vertical são fortemente afetadas pelos gradientes em que estão inseridos os estímulos.

Alves e Fukusima (2007) encontraram uma amplificação dos estímulos, principalmente quando este intercepta o horizonte em presença do gradiente de textura formada por linhas de perspectiva. A superestimação é da ordem de 8 a $10 \%$ no tamanho de objetos situados no centro do campo visual em relação a outro objeto no campo visual inferior. Tais achados ocorreram em apresentações com duração indeterminada, ou seja, os estímulos eram apresentados até que o participante emitisse sua resposta. Isso demonstra mais uma vez a efetividade do gradiente de linhas de perspectiva para informar a distância e, conseqüentemente, afetar a percepção de tamanho.

Outro importante trabalho que reafirma o papel modulador dos indícios de profundidade sobre o tamanho percebido é o de Aks e Enns (1996). Esses autores investigaram o tempo de reação para se localizar objetos de diferentes tamanhos inseridos em gradientes de textura. Em um dos experimentos realizados, verificaram a contribuição relativa de cada um dos gradientes.

Os resultados indicaram que a perspectiva é uma informação mais confiável e rápida na discriminação de tamanho do que a compressão, especialmente nas situações em que o julgamento seria mais fácil (alvos grandes). Com um maior tempo de inspeção, requerido para julgamentos mais difíceis (alvos pequenos), a influência da compressão aumentaria. Além disso, os achados de Aks e Enns (1996) indicaram que a procura pelos alvos foi mais lenta, quando as 
informações de tamanho e distância eram incoerentes, isto é, alvos grandes e próximos e alvos pequenos e distantes.

Isso sugere que o gradiente de textura pode ser processado involuntariamente, ou seja, de maneira rápida, automática e paralela. Esse processamento em paralelo também ocorreria para o tamanho de segmentos de linhas (TREISMAN; GORMICAN, 1988), fazendo com que esta representação pré-atentiva do tamanho seja sensível ao tamanho aparente dos itens, e não apenas ao tamanho retinal (FOUND; MULLER, 2001). Estas são evidências de que o processamento de informações de tamanho ocorreria de baixo para cima (bottom-up), corroborando a abordagem ecológica de Gibson (1979).

Ademais, em pesquisas neurofisiológicas sobre a percepção do tamanho tem-se considerado a descoberta dos substratos biológicos. Um primeiro processamento ocorreria no córtex occipital, especialmente a área V1. Acreditava-se anteriormente que V1 seria um receptor passivo das informações advindas do ambiente, porém estudos recentes indicam que a atividade de V1 reflete não o tamanho do input retiniano, mas sim o tamanho percebido (MURRAY; BOYACI; KERSTEN, 2006) e que ocorre ativação em V1 durante uma ilusão visual de tamanho (MACEVOY; FITZPATRICK, 2006). Estes resultados são consonantes com os apresentados anteriormente advindos de estudos que utilizaram métodos psicofísicos.

Apesar das evidências de um processamento pré-atentivo para a percepção de tamanho associada às informações de profundidade, o modo como a atenção distorce a representação que fazemos do espaço não pode ser esquecida. Os indícios de profundidade sejam eles monoculares (MORITA; KUMADA, 2003, dados semelhantes foram encontrados em chimpanzés por IMURA; TOMONAGA, 2007) ou binoculares (HE; NAKAYAMA, 1995) afetam a alocação de atenção em tarefas de busca visual. 
Resultados semelhantes são encontrados tanto em registros eletrofisiológicos quanto em tarefas comportamentais (PARKS, 2005), sugerindo que a atenção seja eficiente e diferencialmente distribuída para estímulos mais distantes. Outra evidência de que a atenção exerce influência sobre a percepção de tamanho é dada por Anton-Erxleben, Henrich e Treue (2007). Em seus experimentos, quando uma dica é apresentada antes dos estímulos, aquele que foi atendido sofre uma superestimação que pode chegar até a 12\%. Assim, a alocação transitória da atenção faz com que os participantes cometam mais erros no julgamento de tamanho de objetos, especialmente se os estímulos forem pequenos.

Esses resultados além de mostrar o papel modulador dos aspectos atencionais, fornecem indicações de que o tempo de exposição dos estímulos também seria um importante fator envolvido na modulação do tamanho percebido. Trabalhos publicados há várias décadas atrás indicam que exposições breves reduzem o comprimento aparente de uma linha (ERLEBACHER; SEKULER, 1974) e levam a uma perda da constância de tamanho (GULICK; STAKE, 1957).

Outros pesquisadores investigaram como o tamanho percebido afeta a percepção de passagem do tempo (ONO; KAWAHARA, 2007; XUAN et al., 2007). Entretanto, não existem muitos estudos sistemáticos diretamente relacionados com os ajustes de tamanhos e a influência do tempo de exposição dos estímulos.

Um trabalho recente, que tem como tarefa julgar o tamanho relativo em espaços pictóricos e que caminha nessa direção é o de Fukusima, Ferreira-Bacci e Alves (2005). Os autores observaram que, mesmo em apresentações de estímulos por 100ms, houve uma amplificação do tamanho dos objetos situados no centro do campo visual em relação a outro objeto no campo visual inferior. 
Estes resultados suscitam alguns questionamentos, como os que seguem, acerca da interação entre as informações pictóricas de profundidade (gradientes de textura) e o horizonte e o tamanho visualmente percebido, especialmente em exposições breves:

- Sob exposições breves, o horizonte manterá sua forte influência sobre o tamanho percebido em comparação com outras informações pictóricas?

- Tempos de exposição maiores elevariam a influência das outras informações pictóricas sobre o tamanho percebido?

- Tempos de exposição menores manteriam o efeito prevalente da perspectiva sobre o tamanho percebido? 


\section{OBJETIVO GERAL}

Considerando-se a revisão de literatura e as questões levantadas no projeto de pesquisa estabeleceram-se os seguintes objetivos para este trabalho:

- Investigar dentre os gradientes de textura (compressão e perspectiva) qual é o mais prevalente na percepção de tamanho.

- Investigar se o tempo de exposição das informações pictóricas de profundidade é um fator que afeta a comparação de tamanho de objetos pictóricos. 


\section{EXPERIMENTO}

\subsection{OBJETIVO}

Teve-se por objetivo verificar como o tempo de exposição afeta a comparação de tamanho de objetos pictóricos apresentados sob diferentes informações pictóricas de profundidade e o horizonte.

\subsection{MÉTODO}

\subsubsection{Participantes}

Participaram deste estudo cento e vinte voluntários distribuídos em 12 grupos de 10 indivíduos (72 mulheres e 48 homens), alunos da Universidade de São Paulo campus de Ribeirão Preto, com idade entre 18 e 44 anos (média $=24,22$ e desvio-padrão $=3,87$ ), com acuidade visual normal ou corrigida em ambos os olhos (igual ou superior a 6/6). Antes de serem submetidos ao experimento, todos os voluntários assinaram o Termo de Consentimento Livre e Esclarecido (ANEXO A), aprovado pelo Comitê de Ética em pesquisa da FFCLRP-USP (ANEXO B), conforme as normas vigentes no Brasil sobre experimentos com humanos.

\subsubsection{Material e equipamento}

Um computador Pentium IV, 992 MB RAM, com placa de vídeo SiS 661FX, plataforma Windows XP, com o programa Super Lab Pro 2.0 (Cedrus Co.) nele instalado e um monitor LG 
Flatron ez T910B Plus (19”) com resolução de 1024 x 768 pixels e frequiência de atualização de $100 \mathrm{~Hz}$ foram utilizados para a apresentar os estímulos e coletar as respostas dos observadores durante a execução do experimento numa sala escura.

Os estímulos e os fundos de tela foram construídos com o auxílio do programa CorelDraw X3. Os pares de estímulos eram duas barras verticais de cor preta e com luminância de $0,8 \mathrm{~cd} / \mathrm{m}^{2}$ : uma o padrão, de 100 pixels e outra o teste, cujo tamanho variava de 85 a 115 pixels, com diferença de 3 pixels entre eles, totalizando 11 estímulos teste.

Esses pares de estímulos foram apresentados nos seguintes fundos de tela de cor cinza reunidos na Figura 2: sem gradiente de textura com luminância de $51,40 \mathrm{~cd} / \mathrm{m}^{2}$ (a), horizonte com luminância de $50,50 \mathrm{~cd} / \mathrm{m}^{2}$ (b), gradiente de compressão com luminância de $47,90 \mathrm{~cd} / \mathrm{m}^{2}$ (c) e gradiente de perspectiva com luminância de $48,90 \mathrm{~cd} / \mathrm{m}^{2}$ (d). Em cada condição de fundo de tela, a exposição dos pares de estímulos poderia durar 50 ou 100 ou 200 milissegundos.
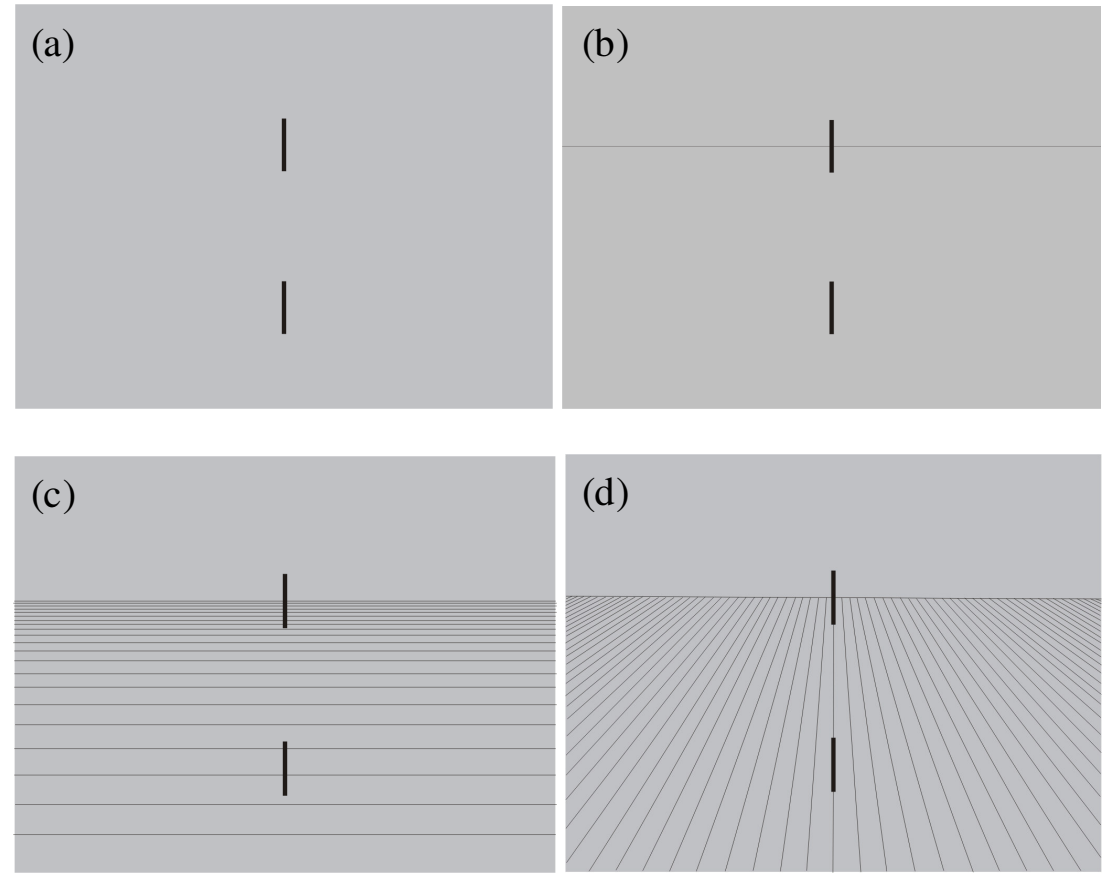

Figura 2: Exemplos de estímulos na situação sem textura (a), na situação com o horizonte (b), na situação com linhas de compressão (c) e na situação com linhas de perspectiva (d). Em todos os exemplos, ambas as barras têm o mesmo tamanho (100 pixels no tamanho original). 
Um apoiador de queixo foi utilizado para que a cabeça do participante se mantivesse imóvel e a uma distância constante de $57 \mathrm{~cm}$ em relação ao monitor. Usou-se um aparelho OrthoRather da Bausch \& Lomb Optical Co. para medir a acuidade visual dos observadores e o Teste de Miles (Dane \& Dane, 2004) para determinar o olho dominante. Também foi usado um oclusor no olho esquerdo para que o participante ficasse com visão monocular (olho direito descoberto).

\subsubsection{Procedimento}

Antes de iniciar o experimento, cada participante teve sua acuidade visual avaliada mediante o aparelho Ortho-Rather da Bausch \& Lomb Optical Co. e fez o Teste de Miles para verificar qual era olho dominante. Os observadores com acuidade normal ou superior em ambos os olhos (6/6 ou superior) puderam participar do experimento. Nenhum participante foi excluído por este critério.

Então os participantes recebiam e liam o Termo de Consentimento Livre e Esclarecido. Caso concordassem com as condições descritas, eles o assinavam, eram designados aleatoriamente a um dos doze grupos e a sessão experimental iniciava-se.

Em sessão individual, os participantes sentavam-se em frente ao monitor para que a altura da cadeira e do apoiador de queixo, localizado a $57 \mathrm{~cm}$ do monitor, fosse ajustada de modo que o olho direito se mantivesse no centro do monitor. Quando esta posição era encontrada e o participante indicava estar confortável, uma venda lhe era colocada no olho esquerdo. Esta venda garantia a realização do experimento em condição monocular direita.

A sessão experimental iniciava-se com a instrução de que seriam apresentadas duas barras verticais aos participantes e estes deveriam indicar em que local da tela (na parte superior ou inferior) foi apresentada a maior barra As respostas eram dadas através do teclado do 
computador. Os voluntários eram instruídos a manter o queixo apoiado e o olhar fixo no centro da tela, onde era disposto um ponto de fixação.

O participante realizava três tentativas para se familiarizar com a tarefa antes do início da coleta das respostas. Antes do início da primeira sessão, ainda na sala, o experimentador certificava-se de que o participante realmente havia compreendido as instruções e, mais uma vez, enfatizava a importância de manter o olhar fixo no centro da tela, ou seja, no ponto de fixação. Ao término da primeira sessão, o voluntário chamava o experimentador e podia descansar pelo tempo que julgasse necessário. Desse modo, o participante é quem determinava o momento do reinício do experimento, isto é, o tempo entre a primeira e a segunda sessão era por ele delimitado.

Os estímulos foram apresentados através do método psicofísico dos estímulos constantes associado ao método de escolha forçada de duas alternativas. No experimento aqui descrito foram utilizados 5 estímulos teste abaixo (85, 88, 91, 94 e 97 pixels) e 5 estímulos teste acima (103, 106, 109, 112 e 115 pixels) do estímulo padrão (100 pixels).

As apresentações foram realizadas em dois blocos, de acordo com a posição do estímulo teste. Em um bloco o estímulo padrão foi apresentado acima do ponto de fixação e o estímulo teste abaixo. No outro bloco, as posições invertiam-se. Essa variação na posição do estímulo teste é fundamental para garantir que os julgamentos sejam baseados naquilo que os participantes realmente vêem e não na memória (NACHMIAS, 2006).

Cada par de estímulos pertencente a um dos blocos (estímulo teste acima ou abaixo) foi apresentado 30 vezes aleatoriamente. As repetições de cada par de estímulos foram igualmente divididas, para que o experimento tivesse duas sessões, com o intuito de reduzir desvios nas respostas ocasionadas pela longa duração deste (BOURNE, 2006). 
Cada tentativa consistiu de exposição prévia de um ponto de fixação no centro da tela por 500ms, seguido pela exposição dos pares de estímulos sobre o fundo de tela, por um tempo de 50 ms, $100 \mathrm{~ms}$ ou $200 \mathrm{~ms}$, dependendo do grupo para o qual o participante foi sorteado. Depois se inseriu uma tela neutra durante 500 ms para minimizar uma possível pós-imagem e logo em seguida uma tela para a coleta da resposta. Após a resposta ser dada, uma tela vazia aparecia e o próximo estímulo era apresentado somente após o participante apertar qualquer tecla. Isso permite que o participante tenha o controle sobre a apresentação dos estímulos. Essa seqüência é apresentada na Figura 3.

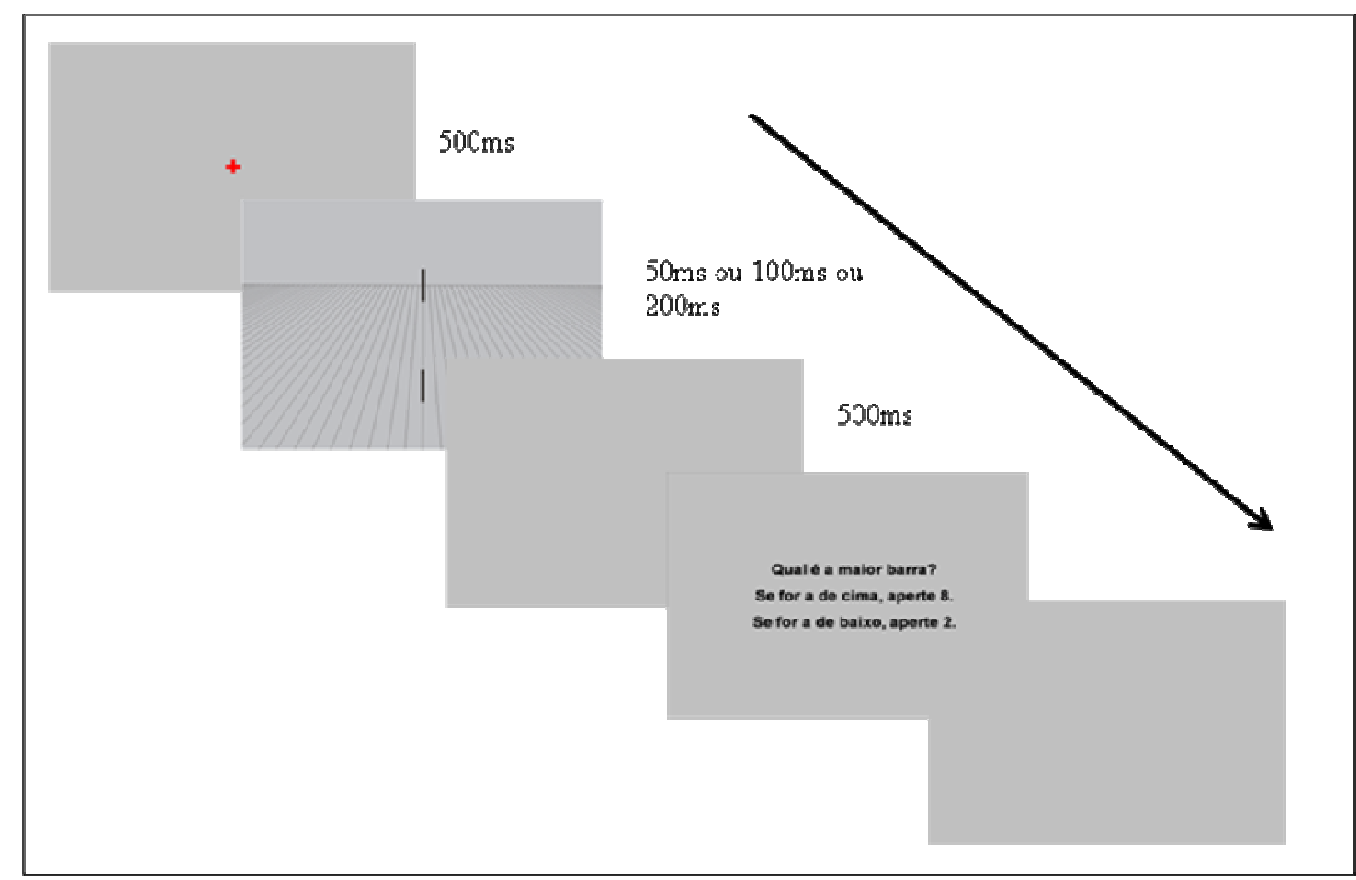

Figura 3: Seqüência de apresentação dos estímulos em cada tentativa. Neste exemplo, as barras são apresentadas na situação com o gradiente de textura de perspectiva. 


\subsubsection{Análise de dados}

Para cada participante foram traçadas curvas psicométricas das comparações de tamanho, uma para cada posição do estímulo teste. Dessa maneira, determinaram-se as inclinações das curvas, os pontos de igualdade subjetiva (PIS) e os erros relativos.

O PIS é a intensidade do estímulo que na média é estimado como igual ao estímulo padrão. Isso significa que seu valor refere-se ao estímulo julgado como maior do que o estímulo padrão em $50 \%$ das tentativas. Seu valor é calculado pelas proporções com que cada estímulo teste foi julgado maior que o estímulo padrão. Considerando que a distribuição destas probabilidades (p) é normal, estas foram convertidas em notação z. A equação de regressão linear dos valores em z permite-nos o cálculo do PIS, que corresponde ao valor de $\mathrm{z}=0$ ( $\mathrm{p}=50 \%)$, isto é, o ponto em que a reta de regressão intercepta o eixo das abscissas (MASIN; VIDOTTO, 1982; GESCHEIDER, 1997).

As inclinações das curvas psicométricas foram obtidas pela equação de regressão linear dos valores em z. Na equação de fórmula $y=a x+b$, o valor de $a$ corresponde à tangente de $\theta$, que é uma medida da inclinação da reta e, conseqüentemente, da curva psicométrica.

A partir do PIS, também se calculou e o erro relativo que é dado pela seguinte fórmula:

$$
\operatorname{Erro}(\%)=100 *(\text { EP-PIS }) / E P,
$$

onde Erro(\%) é o erro relativo e EP é o tamanho do estímulo padrão.

Erro relativo negativo indica que o estímulo teste foi ajustado maior (subestimado) que o estímulo padrão, enquanto um erro relativo positivo demonstra que o estímulo teste foi ajustado menor (superestimado) que o padrão.

Como havia dois blocos de estímulos, um para o estímulo teste acima e outro para o estímulo abaixo do ponto de fixação, o desempenho de cada um dos participantes resultou em 
dois valores de erro relativo e de inclinação da curva psicométrica (as variáveis dependentes deste estudo), os quais foram analisados separadamente.

Os erros relativos e as inclinações das curvas psicométricas foram submetidos a análises de variâncias (ANOVAs), ambas entre participantes e de dois fatores independentes [4 fundos de tela (sem textura, horizonte, gradiente de compressão e gradiente de perspectiva) x 3 tempos de exposição (50ms, 100ms e 200ms)] para se determinar o efeito das condições de fundo de tela, das condições de tempo de exposição dos estímulos e de suas interações nas comparações de tamanho. A análise estatística foi realizada com o auxílio do programa SPSS 15.0. 


\subsection{RESULTADOS}

\subsubsection{Análise dos erros relativos}

O erro relativo foi escolhido como variável dependente, porque fornece valores que independem da unidade de medida e do tamanho dos estímulos utilizados, ao contrário do PIS, o que possibilita comparações entre diferentes estudos. O erro relativo indica o quanto o tamanho do estímulo teste foi superestimado ou subestimado, em porcentagem, mostrando assim o efeito exercido pelos fundos de tela e pelo tempo de exposição sobre as comparações de tamanho.

Os valores médios dos erros relativos para o estímulo teste apresentado no campo visual inferior foram todos negativos, indicando que houve uma subestimação deste. Essa subestimação foi maior para o gradiente de perspectiva nos três tempos analisados como se pode notar na Figura 4, na qual os valores são apresentados em módulo com os respectivos erros padrões da média.

Esse gráfico mostra que na situação sem textura (controle), quanto maior era o tempo de exposição dos estímulos, menores eram os erros de julgamento cometidos pelos participantes. Esse resultado, em conformidade com o esperado, evidencia que sem informações de profundidade, a acurácia no desempenho é maior à medida que há mais tempo para perceber o tamanho dos estímulos.

O contrário ocorreu para os grupos que realizaram as comparações de tamanho no fundo de tela com o horizonte. Observou-se uma elevação dos valores dos erros de julgamentos com o aumento do tempo de exposição. Isso sugere que o horizonte influencia fortemente o tamanho percebido, principalmente em torno de uma exposição de $200 \mathrm{~ms}$.

Apesar do gradiente de perspectiva causar erros relativos maiores nos três tempos de exposição em comparação com o gradiente de compressão, um interessante dado depreende-se de 
uma análise conjunta dos resultados desses gradientes. Em ambos, os erros cometidos em exposições de 50ms e 200ms são muito próximos, sendo os de compressão um pouco menores se confrontados com os de perspectiva. Por outro lado, os maiores erros relativos advieram de julgamentos realizados com estímulos apresentados durante $100 \mathrm{~ms}$, sugerindo uma maior apreensão de informações de profundidade nesse tempo.

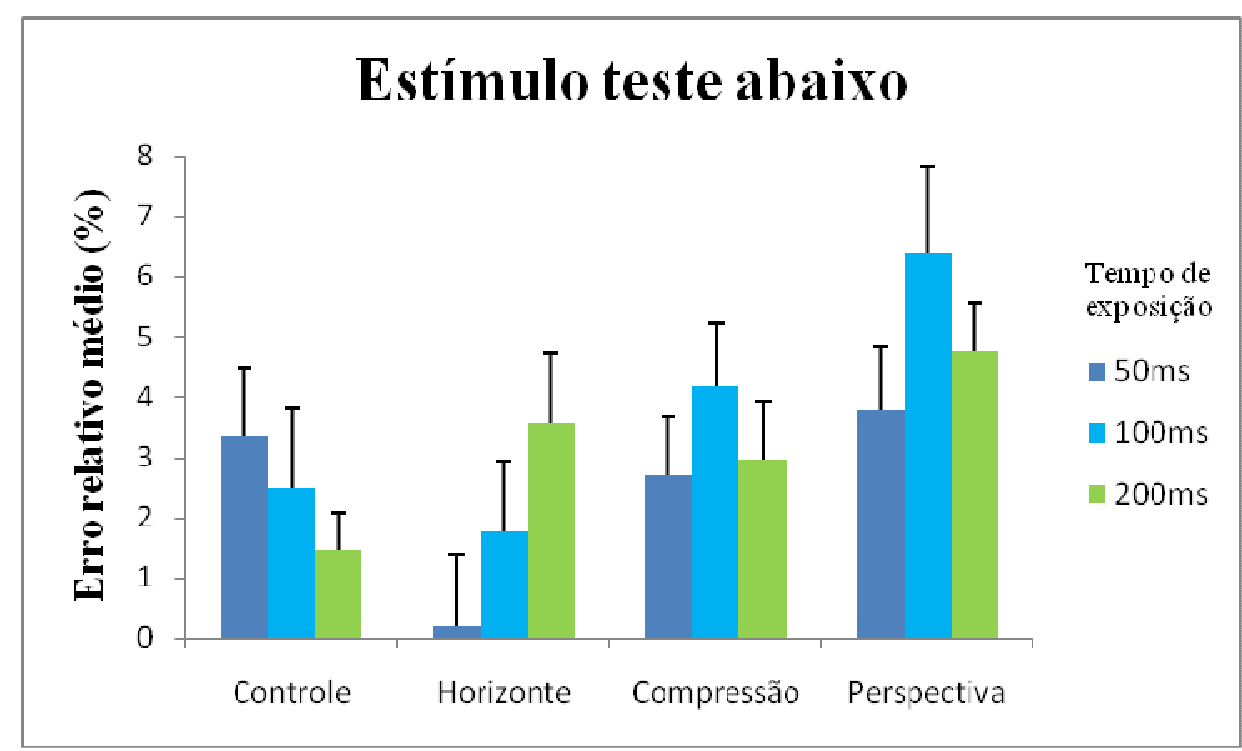

Figura 4: Erros relativos médios (valores modulares) para comparações realizadas com o estímulo teste embaixo, as barras de erro referem-se ao erro padrão da média.

Para verificar se as diferenças observadas entre os fundos de tela e os tempos de exposição eram estatisticamente significativas, os erros relativos foram submetidos a uma análise de variância (ANOVA) entre participantes de dois fatores (4 fundos de tela x 3 tempos de exposição). Antes de realizar a ANOVA, verificou-se através do teste de normalidade de ShapiroWilk que os erros relativos em cada um dos 12 grupos tinham uma distribuição normal ( $>0,05)$. Para se certificar que a exigência de homocedasticidade também era cumprida, foi realizado um teste de Levene, que indicou que a variância entre os grupos era homogênea $(\mathrm{p}=0,590)$. 
A ANOVA não mostrou efeito da interação entre os fatores "fundo de tela" e "tempos de exposição" $[\mathrm{F}(6,108)=1,306, \mathrm{p}=0,261]$ e nem diferença significativa entre os tempos de exposição $[\mathrm{F}(2,108)=1,199, \mathrm{p}=0,305]$. Para o fator "fundo de tela", a análise de variância indicou uma diferença significativa $[\mathrm{F}(3,108)=4,668, \mathrm{p}=0,004]$. O pós-teste de Bonferroni foi aplicado para comparar os quatro fundos de tela, sob os quais foram realizadas as comparações de tamanho.

Verificou-se que a diferença estatisticamente significativa observada entre os fundos teve como principal responsável o gradiente de perspectiva. Esse gradiente apresentou diferenças significativas em relação ao controle $(\mathrm{p}=0,032)$ e ao horizonte $(\mathrm{p}=0,004)$. A despeito da indicação gráfica de que a perspectiva forneceria mais informações de profundidade (maiores erros relativos), a análise estatística não foi suficientemente poderosa para encontrar diferenças significativas entre o gradiente de perspectiva e o de compressão $(\mathrm{p}=0,371)$, contradizendo boa parte da literatura existente sobre o tema.

A apresentação do estímulo teste tanto no campo visual superior quanto no campo visual inferior ensejou eliminar o efeito de memória e aprendizado no julgamento de tamanho, o que já foi mostrado na seção "análise de dados". Desse modo, a opção por realizar duas análises de variâncias separadas deve-se ao fato de que o delineamento experimental não previa uma comparação entre os julgamentos realizados nas duas posições do estímulo teste no campo visual.

Para ratificar a pertinência de uma análise de variância separada, de acordo com a posição do estímulo teste no campo visual foi realizada uma análise de correlação de Pearson. Esse teste indicou que os erros relativos médios para julgamentos realizados nas duas localizações do campo visual têm um grau de correlação de $r=-0,896$ com um nível de significância de $p<0,01$. Isso demonstra que os erros relativos estão altamente correlacionados negativamente nas duas regiões do campo visual. 
Assim, os valores modulares dos erros relativos médios em ambas as posições no campo visual são muito próximos, porém com sinais invertidos. Como já fora exposto, os estímulos teste na parte inferior do campo visual tiveram erros com valores negativos. Por outro lado, os estímulos teste no campo visual superior tiveram erros com valores positivos, indicando que o estímulo teste foi superestimado.

Esses resultados são apresentados na Figura 5 e nota-se sua semelhança aos da Figura 4. Os maiores erros de julgamento concentraram-se no gradiente de linhas de perspectiva. Além disso, à medida que o tempo de exposição aumentava, os participantes apresentavam um desempenho melhor na situação sem textura e pior na situação com o horizonte apenas. Mais uma vez, observou-se uma maior quantidade de erros para comparações sob apresentações de 100ms na presença das informações pictóricas de profundidade, sejam elas derivadas de um gradiente formado por linhas de perspectiva ou por linhas de compressão.

No entanto, observa-se uma diferença. Os erros relativos médios para a situação em que o estímulo teste encontrava-se no campo visual inferior (Figura 4) são maiores do que os da situação em que o estímulo teste era exposto acima (Figura 5), sugerindo uma maior acurácia para o julgamento dos estímulos localizados na porção superior do campo visual. 


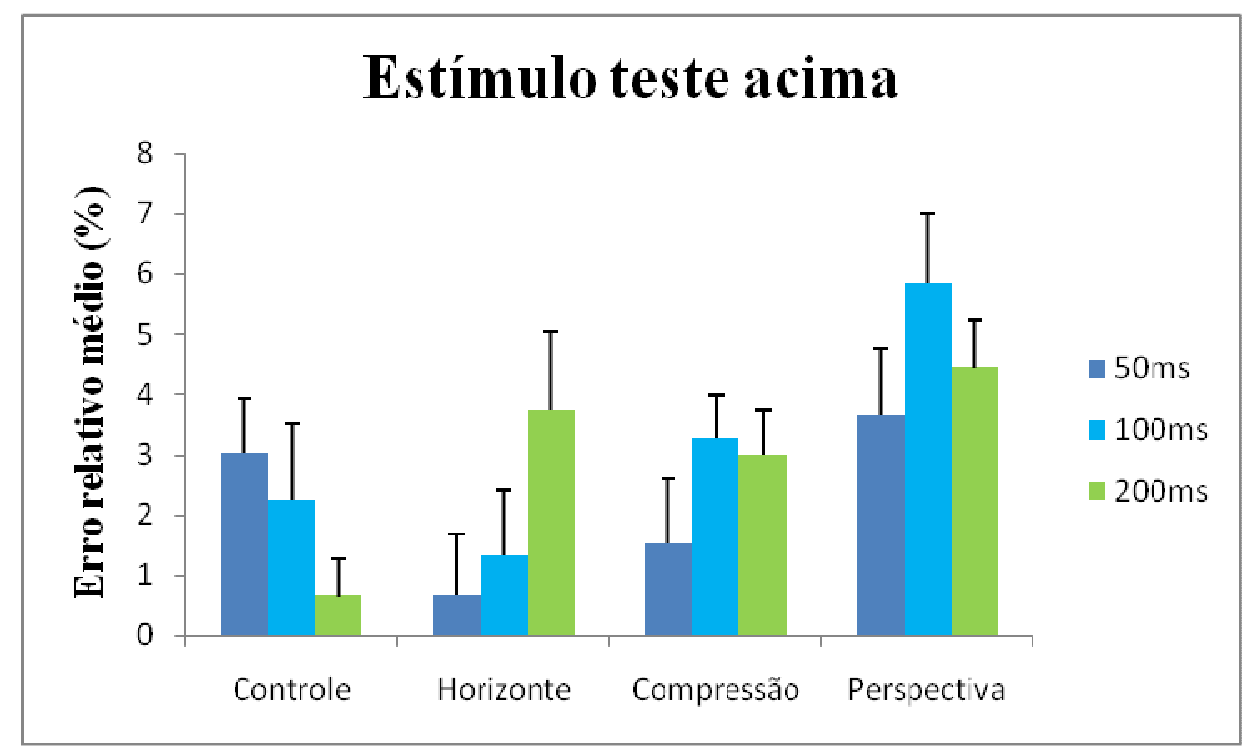

Figura 5: Erros relativos médios para comparações realizadas com o estímulo teste acima, as barras de erro referem-se ao erro padrão da média.

Os erros relativos das comparações de tamanho dos estímulos teste no campo visual superior também foram submetidos a uma ANOVA. Novamente, antes de esta ser realizada, verificou-se pelo teste de normalidade Shapiro-Wilk ( $>0,05)$, se os dados obedeciam a uma distribuição normal, e, por meio do teste de Levene $(p=0,532)$, se as variâncias entre os grupos eram homogêneas.

A ANOVA também não revelou uma interação significativa entre os fatores "fundo de tela" e "tempo de exposição" $[\mathrm{F}(6,108)=1,724, \mathrm{p}=0,122]$ e nem diferenças significativas entre as três condições de tempo $[\mathrm{F}(2,108)=1,004, \mathrm{p}=0,370]$. Outra vez, os fundos de tela mostraram ser estatisticamente diferentes entre si $[\mathrm{F}(3,108)=4,856, \mathrm{p}=0,005]$. Para descobrir quais níveis desse fator foram responsáveis por essa diferença, foi realizado o pós-teste de Bonferroni.

Constatou-se que o gradiente de perspectiva difere significativamente da situação sem textura $(\mathrm{p}=0,009)$ e da situação com o horizonte $(\mathrm{p}=0,007)$, porém não foram observadas diferenças entre o gradiente de perspectiva e o gradiente de compressão $(\mathrm{p}=0,086)$. A análise dos erros relativos médios para as duas posições do estímulo teste no campo de visão forneceu 
resultados muito similares. A partir desses, depreende-se que as informações pictóricas de profundidade, principalmente o gradiente de perspectiva, e o tempo de exposição dos estímulos são dois importantes moduladores do tamanho visualmente percebido.

\subsubsection{Análise das inclinações das curvas psicométricas}

A inclinação de uma curva psicométrica oferece informações sobre a sensibilidade individual dos participantes em discriminar os diversos estímulos que lhes foram apresentados. Assim, a compreensão de como o desempenho dos participantes modificava-se com a variação da intensidade dos estímulos teste fornece subsídios imprescindíveis para uma correta interpretação dos resultados obtidos em tarefas como comparar tamanhos.

Na figura 6 foram dispostos os resultados das médias das inclinações das curvas psicométricas para as comparações realizadas com as duas posições do estímulo teste no campo visual. Na coluna da esquerda estão os resultados das comparações com o estímulo teste acima do estímulo padrão nos quatro fundos de tela.

Observa-se que as inclinações das curvas psicométricas para os três tempos de exposição são muito próximas nas condições sem textura e com o horizonte. As curvas apenas deslocam-se lateralmente, o que denota as variações dos valores do PIS, de acordo com o tempo de exposição. Já para as condições com informações pictóricas de profundidade (gradiente de compressão e de perspectiva) nota-se que as curvas para os julgamentos realizados sob o tempo de 50ms têm uma inclinação menor do que para os realizados nos tempos de 100ms e 200ms (Figura 6e e 6g). 


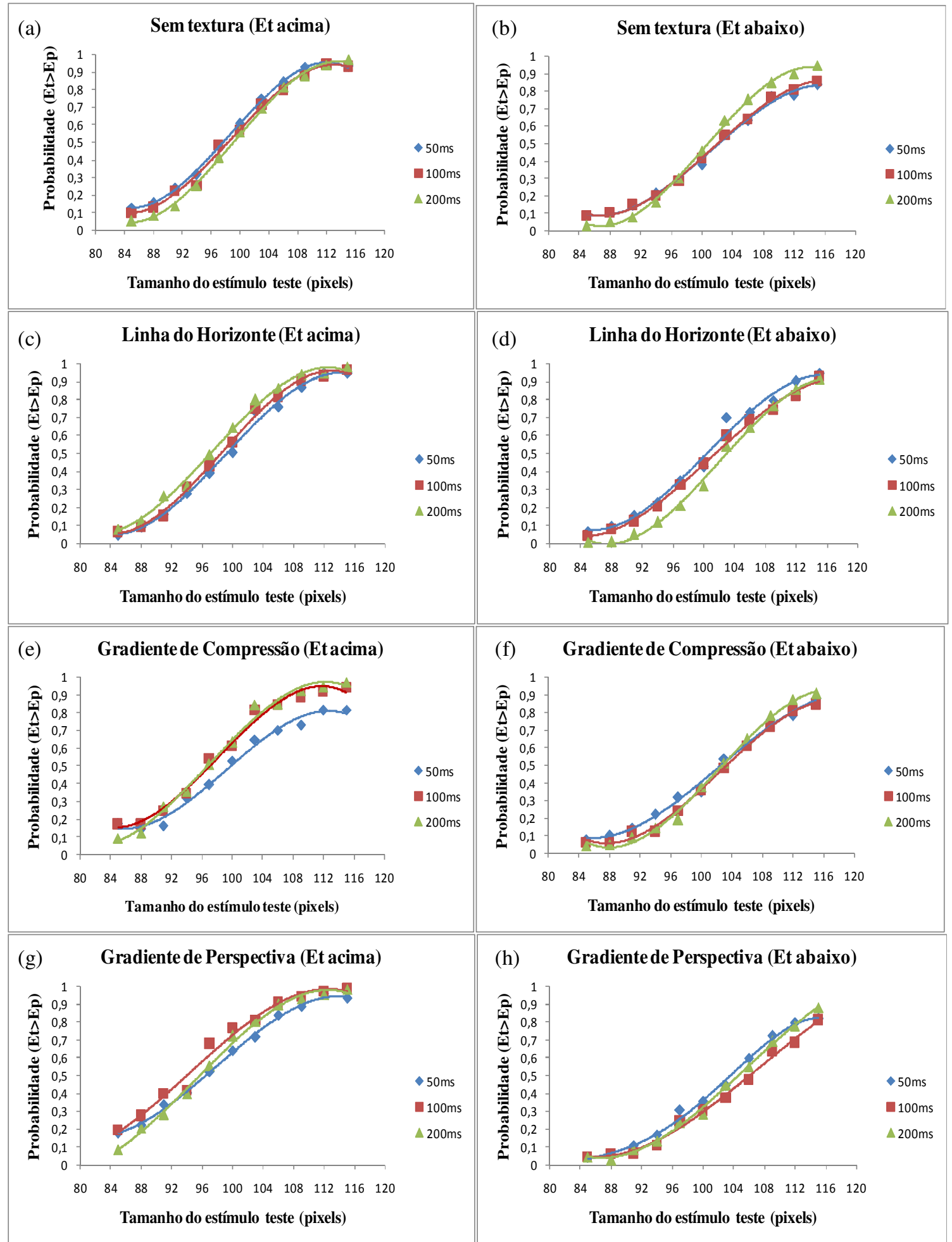

Figura 6: Curvas psicométricas médias para as comparações realizadas sob os diferentes tempos de exposição (50ms, $100 \mathrm{~ms}$ e $200 \mathrm{~ms}$ ). No eixo das ordenadas estão dispostas as probabilidades com que o estímulo teste (Et) é julgado maior que o estímulo padrão (Ep). No eixo das abcissas estão colocados os valores dos Et em pixels. Cada gráfico apresenta os resultados, de acordo com os fundos de tela (sem textura, horizonte, gradiente de compressão ou gradiente de perspectiva) e a posição dos Et em relação ao Ep. 
Com o intuito de averiguar se as diferenças observadas eram estatisticamente significativas aplicou-se uma ANOVA de dois fatores, sendo estes o "fundo de tela" e o "tempo de exposição". As exigências de distribuição normal dos dados $(\mathrm{p}>0,05)$, verificada pelo teste de Shapiro-Wilk, e de homocedasticidade das variâncias entre os grupos $(\mathrm{p}=0,381)$, conferida pelo teste de Levene, foram satisfeitas e, por isso, deu-se prosseguimento à análise de variância.

A ANOVA não encontrou interação entre os fatores $[\mathrm{F}(6,108)=0,379, \mathrm{p}=0,891]$ e nem diferenças estatisticamente significativas entre os quatro fundos de tela $[F(3,108)=2,343$, $\mathrm{p}=0,077]$. Por outro lado, foram evidenciadas diferenças entre os tempos de exposição $[\mathrm{F}(2,108)=3,312, \mathrm{p}=0,04]$. Através do pós-teste de Bonferroni, verificou-se que a maior diferença observada ocorreu entre os tempos de exposição de $50 \mathrm{~ms}$ e $200 \mathrm{~ms}$ ( $\mathrm{p}=0,036)$, os quais não diferiram significativamente do tempo de $100 \mathrm{~ms}$ ( $\mathrm{p}=0,935$, em comparação com o tempo de 50ms e p=0,380, em relação ao de $200 \mathrm{~ms}$ ).

Ainda na Figura 6, mostram-se na coluna da direita as curvas psicométricas médias para as comparações de tamanho com o estímulo teste abaixo do estímulo padrão para os quatro fundos de tela. Nota-se que para os quatro fundos de tela, principalmente para as condições sem textura e com linha do horizonte (6b e 6d), as curvas são mais inclinadas para os julgamentos feitos sob o tempo de exposição de $200 \mathrm{~ms}$, denotando uma maior sensibilidade para perceber as diferenças de tamanho nesse tempo.

Para verificar se essas diferenças eram estatisticamente significativas realizou-se uma ANOVA entre participantes de dois fatores ("fundo de tela" e "tempo de exposição"). A exigência de que os dados tenham uma distribuição normal foi conferida, por meio do teste de Shapiro-Wilk, e satisfeita $(p>0,05)$. O requisito de que as variâncias entre os grupos sejam homogêneas, verificada pelo teste de Levene, foi violado ( $\mathrm{p}=0,006)$. Entretanto, a análise de variância é robusta o bastante para contornar essa violação, desde que se tenha o mesmo número 
de participantes em cada uma das situações (DANCEY; REIDY, 2006; HAIR, 2005). Por satisfazer essa condição, a ANOVA foi realizada.

A ANOVA, como a anterior para comparações com o estímulo teste acima, não encontrou interação entre os dois fatores $[\mathrm{F}(6,108)=0,319, \mathrm{p}=0,926]$ e nem diferenças significativas entre os fundos de tela $[\mathrm{F}(3,108)=2,599, \mathrm{p}=0,056]$. No entanto, encontrou-se diferenças estatisticamente significativas para os distintos tempos de exposição $[\mathrm{F}(2,108)=6,007, \mathrm{p}=0,003]$. O pós-teste de Bonferroni foi realizado para descobrir em quais dos níveis localizava-se o principal efeito responsável por essa diferença.

Verificou-se que a diferença fundamental encontrava-se entre os tempos de $50 \mathrm{~ms}$ e $200 \mathrm{~ms}$ ( $\mathrm{p}=0,003$ ), enquanto a diferença entre o tempo de exposição de $100 \mathrm{~ms}$ e os tempos de $50 \mathrm{~ms}$ $(\mathrm{p}=0,841)$ e $200 \mathrm{~ms}(\mathrm{p}=0,069)$ não foi significativa. Esse resultado está de acordo com a expectativa de que um maior tempo de exposição dos estímulos melhora a capacidade dos participantes em discriminar pequenas alterações de tamanho.

Em conjunto, as duas ANOVAs sugerem que os diferentes fundos de tela não exerceram forte influência sobre a capacidade de discriminação dos voluntários. Por outro lado, evidencia o grande papel modulador que o tempo de exposição tem sobre a sensibilidade discriminatória dos participantes, principalmente na tarefa de comparar tamanhos de objetos pictóricos, cuja variação entre os estímulos é bastante restrita. 


\subsection{DISCUSSÃO}

Os erros relativos das comparações de tamanho nos informam sobre quão efetivos foram os fundos de tela para informar distância e, também, como os diferentes tempos de exposição modularam o tamanho percebido. A média dos erros relativos para o gradiente formado por linhas de perspectiva foi maior do que a média para aquele formado por linhas de compressão. Nota-se uma grande subestimação, superior a 6\%, do estímulo teste apresentado no campo visual inferior, com o gradiente de linhas de perspectiva e sob um tempo de 100ms.

Este achado é semelhante aos de Fukusima, Ferreira-Bacci e Alves (2005), que utilizaram as mesmas condições (tempo e gradiente). Esses autores manipularam a posição do estímulo no campo visual superior, ora apresentado abaixo do horizonte, ora interceptando-a e ora acima da linha do horizonte. Os resultados são concordantes, pois a superestimação do estímulo foi maior quando este interceptava o horizonte, posição essa escolhida para a apresentação dos estímulos no presente trabalho.

Entretanto, a análise estatística realizada não foi suficientemente poderosa para encontrar diferença significativa entre os gradientes de perspectiva e de compressão, que é descrita em vários estudos anteriores (AKS; ENNS, 1996; ALVES; FUKUSIMA, 2007; CUTTING; MILLARD, 1984; GOODENOUGH; GILLIAM, 1997; TOZAWA; OYAMA, 2006). Provavelmente, diferenças metodológicas explicam o porquê desses resultados distintos. Por exemplo, a tarefa aqui proposta aos participantes (comparar tamanhos) era diferente da realizada nesses estudos acima citados (estimar distância). Não se pode negligenciar, ainda, a restrição do tempo de exposição dos estímulos e das informações de profundidade como um fator passível de responder por tais dissimilaridades. 
Os fundos de tela utilizados nessa dissertação podem ser responsáveis por tais contradições. Os gradientes de textura, tanto o de perspectiva quanto o de compressão, foram apresentados em conjunto com o horizonte. Desse modo, as informações de profundidade não estavam dispostas na terça parte superior do fundo de tela. Como a influência do horizonte na percepção de tamanho já foi extensamente descrita (ALVES; FUKUSIMA, 2005; BERTAMINI; YANG; PROFFITT, 1998; ROGERS, 1996), ele poderia “mascarar" os efeitos dos gradientes. Desse modo, os resultados observados seriam devidos apenas ao efeito do horizonte sobre o tamanho percebido.

Essa interpretação pode ser refutada pela análise do efeito modulador do tempo de exposição sobre as comparações de tamanhos nos quatro fundos de tela utilizados. Para a situação com o horizonte, observou-se um aumento dos erros relativos à medida que os tempos de exposição eram maiores. Por outro lado, os fundos de tela com informações de profundidade tiveram seus maiores erros observados aos $100 \mathrm{~ms}$, indicando que a apreensão destas foi mais proeminente com esse tempo.

Tomados em conjunto, esses resultados permitem-nos afirmar que, para afetar a percepção de tamanho, o horizonte requer maiores tempos de exposição do que os gradientes de textura. Assim, os efeitos do gradiente de textura e o horizonte sobre o tamanho relativo são independentes e modulados diferencialmente pelo tempo. Portanto, conclui-se que são reduzidas as chances de que o horizonte tenha encoberto o efeito dos gradientes, gerando resultados semelhantes para as comparações efetuadas sob as linhas de compressão e de perspectiva.

De modo distinto à situação com o horizonte, os maiores erros relativos observados aos 100ms em julgamentos com os indícios de profundidade presentes (perspectiva e compressão) foi em direção contrária às expectativas de que maiores tempos de exposição resultariam em um processamento mais eficaz de tais informações. Essa é uma evidência de que as informações 
pictóricas de profundidade têm um tempo ótimo, em torno de $100 \mathrm{~ms}$, sob o qual seu efeito na modulação no tamanho percebido é maximizado.

O padrão de resultados similares de maximização do processamento da informação de profundidade aos 100ms, observados entre o gradiente de perspectiva e o de compressão, encontra respaldo no estudo de Tsutsui et al. (2002). Esses autores mostraram que a ativação de neurônios seletivos a superfícies por gradiente de textura, presentes na parte caudal e porção lateral do sulco intraparietal, independe do gradiente de textura utilizado.

Esses resultados são coerentes com àqueles observados em outros estudos com medidas eletrofisiológicas, como é o de DiLollo, Enns e Resink (2000). Neste trabalho, os autores investigaram o fenômeno da consciência dos eventos visuais e mostraram que é preciso um tempo de 120ms para que os neurônios da área V1 do córtex occipital respondam a informações de superfícies, como é o caso dos gradientes de textura.

Em outro estudo com objetivos e resultados semelhantes, Tong (2003) discutiu que os mecanismos tardios de ativação de V1 ocorrem entre 80 e 100ms. Isso significa que para um alvo tornar-se consciente, condição necessária para que o observador realize julgamentos, um tempo próximo a 100ms é requerido para que, através de processos de retroalimentação, as áreas extraestriadas enviem as informações para V1.

Apesar de mostrarem valores um pouco diferentes, variando de 80 a 120ms, estes resultados não contradizem os achados do experimento aqui exposto. $\mathrm{O}$ desempenho em comparar tamanhos não foi mensurado sob tais tempos, dada a limitação imposta pelo próprio método, no qual os tempos foram previamente escolhidos.

A maximização encontrada aos $100 \mathrm{~ms}$ serve de indicativo de que a maior efetividade de processamento dos indícios pictóricos de profundidade ocorra numa faixa de tempo próxima a esse tempo de exposição, o que é corroborado pelos estudos de DiLollo, Enns e Resink (2000) e 
Tong (2003). Portanto, novas investigações psicofísicas são necessárias para revelar com maior rigor a faixa de tempo em que ocorre a real maximização desse processamento.

Nota-se que os autores supracitados são defensores que o processamento da informação visual ocorra de modo hierárquico e reverso. Desse modo, estruturas corticais de alta ordem estariam envolvidas primariamente nesse processamento. Um estudo recente com técnicas de imageamento cerebral apresenta uma posição diferente (MURRAY; BOYACI; KERSTEN, 2006), porém com resultados que também se coadunam com os aqui discutidos.

Esses autores encontraram que a atividade da área cortical V1 reflete o tamanho percebido e não simplesmente o tamanho "real" que chega à retina. Assim, as informações dispostas no ambiente (dicas de profundidade, por exemplo) não precisariam ser processadas por estruturas mais elevadas na hierarquia cerebral para exercerem influência na percepção de tamanho.

De todo modo, independentemente de questões referentes ao processamento da informação visual, se reverso ou não, todos os resultados discutidos conformam-se aos apresentados nesta dissertação, ou seja, a apreensão dos indícios pictóricos de profundidade é realizada muito rapidamente, sendo estes importantes moduladores do tamanho visualmente percebido.

Observou-se ainda um desempenho similar entre as comparações realizadas sob os tempos de $50 \mathrm{~ms}$ e $200 \mathrm{~ms}$ nas duas condições com gradientes de textura (perspectiva e compressão). Possivelmente isso se deva à insuficiência de tempo aos 50ms para que os indícios de profundidade sejam eficientemente processados ou mesmo detectados. Tsutsui et al. (2002) defendem que o gradiente de textura não é um indício de profundidade per se, isto é, só informa distância após serem detectados.

Por outro lado, movimentos oculares ocorrem amiúde em tempos superiores aos 150ms (BOURNE, 2006), o que leva a concluir que o tempo de exposição de 200ms era suficiente para 
que estes movimentos estivessem presentes. Desse modo, é bastante provável que os participantes tiveram tempo para "vasculhar" a imagem e para que algum tipo de correção cognitiva se iniciasse. Uma possibilidade é a alocação da atenção, um componente essencial para a preparação e/ou execução de movimentos oculares (CORBETTA et al., 1998; HOFFMAN; SUBRAMANIAM, 1995).

Há evidências recentes de que a relação entre atenção e movimentos sacádicos não é obrigatória e nem imediata, embora compartilhem circuitos anatômicos e sejam processos paralelos que funcionam em harmonia (AWH; ARMSTRONG; MOORE, 2006; VAN DER LUBBE et al., 2006; NEGGERS et al., 2007; JUAN et al., 2004, 2008). Assim, a atenção melhoraria o desempenho dos participantes em comparar tamanhos, o que é evidenciado pela diminuição dos valores dos erros relativos.

Analisar a diferença entre as comparações de tamanho nas duas posições distintas do campo visual não configurava entre os objetivos iniciais deste trabalho. Contudo, os resultados mostraram uma pequena diferença no desempenho dos participantes, de acordo com a posição do estímulo teste.

Consistentemente com os resultados de Fukusima e Faubert (2001), observou-se um julgamento mais acurado quando o estímulo teste estava na parte superior do campo de visão. Tal ocorrência corrobora a hipótese de que a percepção de tamanho é anisotrópica, isto é, objetos podem ser percebidos como de tamanhos distintos por estarem em diferentes posições no espaço, a despeito de terem o mesmo ângulo visual.

Os erros relativos, quase $2 \%$, ocorreram mesmo na ausência das informações pictóricas de profundidade (condição sem textura) e com o maior tempo de exposição utilizado (200ms). Resultados similares foram descritos por Alves e Fukusima (2007), que encontraram uma superestimação de $3 \%$ de estímulos apresentados no centro do campo visual comparados a outro 
disposto no campo visual inferior. Esses dados dão suporte à idéia de que a percepção do espaço é realmente anisotrópica.

Ainda não há explicação definitiva para tal fenômeno, embora duas hipóteses mereçam destaque. A primeira é de Previc (1990), com inspiração claramente evolutiva, segundo o qual o campo visual superior e o campo visual inferior responderiam a diferentes demandas, forjadas durante a evolução de nossa espécie. Assim, o campo visual superior evoluíra para o processamento de informações distantes, enquanto o inferior atenderia ao fluxo de informações proximais.

Nos trabalhos de Carrasco (LIU; HEEGER; CARRASCO, 2006; TALGAR; CARRASCO, 2002) encontra-se que o desempenho humano varia de acordo com a posição no espaço, o que é marcadamente acentuado no meridiano vertical, fenômeno esse chamado de "assimetria do meridiano vertical". Os resultados indicam que o desempenho, em tarefas de segregar textura, é melhor no campo visual inferior. Nos referidos estudos, essa diferença ocorreria por motivos sensoriais (restrições visuais, por exemplo) e não por alocação diferenciada de atenção.

O melhor desempenho para o campo visual inferior, nos trabalhos de Carrasco, não é inconsistente com os resultados apresentados. É fundamental salientar que esse melhor desempenho refere-se às tarefas de sensibilidade ao contraste e resolução espacial. Estas são necessárias, principalmente, para o processamento de imagens ricas em detalhes e para a percepção visual da forma (SANTOS; SIMAS, 2001), o que não ocorre nos estímulos construídos para o trabalho ora em discussão.

A inclinação da curva psicométrica fornece importantes informações sobre a sensibilidade dos sistemas sensoriais à medida que a intensidade da estimulação aumenta. Esperava-se que fosse encontrada uma relação direta entre as inclinações e os tempos de exposição. Isto é, maiores 
inclinações, denotando maior capacidade de discriminação, seriam observadas em comparações realizadas sob maiores tempos de exposição.

Em conformidade com as expectativas, a análise da média das inclinações revelou uma melhora no desempenho dos observadores em perceber mudanças discretas no tamanho dos estímulos sob exposições de tempo maiores. O desempenho nessa tarefa melhorou gradualmente, assim os resultados apontaram inclinações menores no tempo de 50ms, com valores intermediários aos 100ms e maiores aos 200ms. Esse padrão foi observado independentemente do fundo de tela utilizado e da posição do estímulo teste.

Esses resultados podem ser compreendidos através do efeito da atenção transitória, que é alocada involuntariamente a um estímulo que aparece brevemente no campo visual (NAKAYAMA; MACKEBEN, 1989), como é o caso de nosso experimento. Desse modo, podese pensar que maiores tempos de exposição aumentarão a possibilidade de que a atenção exerça alguma influência sobre o desempenho dos participantes para realizarem comparações de tamanho.

Ao estudarem o efeito da atenção transitória sobre a curva psicométrica, Cameron, Tai e Carrasco (2002) encontraram que o limiar e a inclinação da curva - esta de maneira bem modesta - diminuem com a atenção em uma tarefa de sensibilidade ao contraste. Essa diminuição da inclinação, diferentemente de nossos resultados, pode ter ocorrido por serem tarefas distintas nos dois estudos. De todo modo, os próprios autores afirmam que essa diminuição não foi conclusiva e discutem a dificuldade no cálculo da inclinação. Dificuldade essa também exposta por Gilchrist, Jerwood e Ismaiel (2005), que debatem o problema da comparação de inclinações, encontrado em diferentes estudos pelo uso de métodos diferentes.

Cameron, Tai e Carrasco (2002) ainda afirmaram que seus resultados indicam que a atenção não afetaria posições no campo visual diferencialmente, corroborando o achado de que o 
aumento do tempo de exposição, e do efeito da atenção conseqüentemente, ocorreu independentemente da posição do estímulo teste.

Ademais, observaram-se menores inclinações da curva psicométrica na presença dos gradientes de textura, indicando que a realização da tarefa nessas condições tornava-se mais difícil. Em oposição, as maiores inclinações foram encontradas nas situações sem textura (controle) e na com o horizonte.

No primeiro caso, o desempenho dos participantes alcançava um alto nível de acurácia, provavelmente pela pequena quantidade de informação a ser processada em comparação com a existente nos gradientes de textura. Já na condição com o horizonte, estudos prévios já citados anteriormente (ALVES; FUKUSIMA, 2005; BERTAMINI; YANG; PROFFITT, 1998; ROGERS, 1996) apresentam a grande repercussão do horizonte sobre o tamanho relativo, o que explica a melhora na sensibilidade dos participantes nessa condição. 


\section{CONSIDERAÇÕES FINAIS}

Em face das questões formuladas na Introdução e dos objetivos estabelecidos, pode-se reconhecer que o horizonte é uma informação pictórica de profundidade que afeta intensamente o tamanho relativo. Essa evidência depreende-se das maiores inclinações das curvas psicométricas para essa condição, revelando que o horizonte incrementa a sensibilidade do participante em perceber alterações sutis no tamanho dos estímulos. Todavia, os resultados dos erros relativos indicam que essa influência é sutil em exposições breves e sugerem que ela se inicia por volta dos $200 \mathrm{~ms}$.

Por outro lado, maiores tempos de exposição não significaram maior efetividade para informar a distância e, assim, afetar a percepção de tamanho nas comparações feitas sob os gradientes de textura de perspectiva e de compressão. Observou-se o interessante dado de haver uma maximização para captar as informações contidas nos gradientes aos 100ms, com um desempenho semelhante entre os tempos de $50 \mathrm{~ms}$ e de $200 \mathrm{~ms}$.

Estudos eletrofisiológicos anteriores também apontaram uma faixa de tempo semelhante, oscilando entre 80 e 120 ms. Contudo, esses resultados não permitem afirmar com exatidão qual seria o tempo ótimo, no qual o processamento das informações de distância alcançaria seu ápice, modulando com mais eficiência a percepção de tamanho.

A despeito do fato de que diferenças significativas entre o gradiente de perspectiva e o de compressão não terem sido apontadas, o primeiro apresentou uma tendência de ser mais informativo sobre a distância em todos os tempos analisados. Desse modo, a perspectiva mantém seu efeito prevalente mesmo sob um tempo de exposição bastante restrito em comparação com os outros fundos de tela estudados. Conclui-se, portanto, pelo amplo efeito modulador dos tempos 
de exposição sobre comparações de tamanho de estímulos inseridos em contextos com indícios pictóricos de profundidade.

Enfim, a visão, por sua abrangente influência e repercussão na constituição de uma suposta realidade, sofre um processo de "naturalização". Isto é, fenômenos surpreendentes passam despercebidos. O fato de "habitarmos" um mundo tridimensional, apesar de nossa estrutura primária para a visão (a retina) ser bidimensional não causa espanto aos mais distraídos.

A dissertação apresentada é uma pequena e humilde contribuição para elucidar aspectos sobre este mundo em três dimensões, como a percepção de distância e tamanho. Novos estudos ainda são necessários para que os resultados apresentados consolidem-se e adquiram consistência frente a novas pesquisas. 


\section{REFERÊNCIAS}

AKS, D. J.; ENNS, J. T. Visual search for size is influenced by a background texture gradient. Journal of Experimental Psychology: Human Perception and Performance, v. 22, n. 6, p. 1467-1481, 1996.

ALLISON, R. S.; HOWARD, I. P. Temporal dependencies in resolving monocular and binocular cue conflict in slant perception. Vision Research, v. 40, n. 4, p. 1869-1885, 2000.

ALVES, N. T.; FUKUSIMA, S. S.. Efeitos de instruções e do horizonte nos julgamentos de tamanhos relativos pictóricos. Psicologia: Teoria e Pesquisa, v. 21, n. 2, p. 157-162, 2005.

ALVES, N. T.; FUKUSIMA, S. S. Gradientes de textura com linhas de perspectiva e horizonte amplificam a superestimação de tamanho relativo em espaços pictóricos. Psicologia: Reflexão e Crítica, v. 20, n. 1, p. 35-42, 2007.

ANDERSEN, G. J.; BRAUNSTEIN, M. L.; SAIDPOUR, A. The perception of depth and slant from texture in three-dimensional scenes. Perception, v. 27, p. 1087-1106, 1998.

ANTON-ERXLEBEN, K.; HENRICH, C.; TREUE, S. Attention changes perceived size of moving visual pattern. Journal of Vision, v. 7, n. 11, p. 1-9, 2007.

AWH, E.; ARMSTRONG, K. M.; MOORE, T. Visual and oculomotor selection: links, causes and implications for spatial attention. Trends in Cognitive Science, v. 10, n. 3, p. 124-130, 2006.

BARBET, I.; FAGOT, J. Perception of the corridor illusion by baboons (Papio papio). Behavioural Brain Research, v. 132, p. 111 - 115, 2002.

BENNETT, D.; WARREN, W. Size scaling: Retinal or environmental frame of reference. Perception \& Psychophysics, v. 64, n. 3, p. 462-477, 2002.

BERTAMINI, M.; YANG, T. L.; PROFFITT, D. R. Relative size perception at a distance is best at eye level. Perception \& Psychophysics, v. 60, n. 4, p. 673-682, 1998.

BINGHAM, G. P. Perceiving the size of trees: biological form and the horizon ratio. Perception \& Psychophysics, v. 54, p. 485-495, 1993.

BOURNE, V. J. The divided visual field paradigm: methodological considerations. Laterality, v. 11, n. 4, p. 373-393, 2006. 
BRUGGEMANN, H.; YONAS, A.; KONCZAK, J. Processing linear perspective information for perception and action: The effects of binocular and monocular presentation. Neuropsychologia, v. 45, n.7, p. 1420-1426, 2007.

CAMERON, E. L.; TAI, J. C.; CARRASCO, M. Covert attention affects the psychometric function of contrast sensitivity. Vision Research, v. 42, p. 949-967, 2002.

CAVOTO, B. R.; COOK, R. G. The contribution of monocular depth cues to scene perception by pigeons. Psychological Science, v. 17, p. 628-634, 2006.

CORBETTA, M. et al. A common network of functional areas for attention and eye movements. Neuron, v. 21, p. 761-773, 1998.

CORNSWEET, T. The staircase method in psychophysics. American Journal of Psychology, v. 75 , p. 485-491, 1962.

CUTTING, J. E.; MILLARD, R. T. Three gradients and the perception of flat and curved surfaces. Journal of Experimental Psychology: General, v. 113, n. 2, p. 198-216, 1984.

DAI, H. On measuring psychometric functions: A comparison of the constant-stimulus and adaptive up-down methods. The Journal of the Acoustical Society of America, v. 98, n. 6, p. 3135-3139, 1995.

DANCEY, C. P.; REIDY, J. Estatística sem matemática para a Psicologia. 3 ed. Porto Alegre, RS: Artmed, 2006.

DANE, A.; DANE, S. Correlations among handedness, eyedness, monocular shifts from binocular focal point and nonverbal intelligence in university mathematics students. Perceptual and Motor Skills, v. 99, p. 519-524, 2004.

DA SILVA, J. A. et al. Acerca da métrica da percepção do espaço visual. Arquivos Brasileiros de Oftalmologia, v. 69, n. 1, p. 127-35, 2006.

DILOLLO, V.; ENNS, J. T.; RESINK, R. A. Competition for consciousness among visual events: the psychophysics of reentrant visual processes. Journal of Experimental Psychology:General, v. 129, n. 4, p. 481-507, 2000.

DIXON, M. W. et al. Eye height scaling of absolute size in immersive and nonimersive displays. Journal of Experimental Psychology: Human Perception and Performance, v. 26, n. 2, p. 582-593, 2000.

ERLEBACHER, A.; SEKULER, R. Response frequency equalization: A bias model for psychophysics. Perception \& Psychophysics, v. 9, n.3-A, p. 315-320, 1971. 
ERLEBACHER, A.; SEKULER, R. Perceived length depends on exposure duration: straight lines and Müller-Lyer stimuli. Journal of Experimental Psychology, v. 103, n. 4, p. 724-728, 1974.

EPSTEIN, W.; PARK, J.; CASEY, A. The current status of the size-distance hypotheses. Psychological Bulletin, v. 58, n. 6, p. 491-514, 1974.

FOLEY, J. M.; RIBEIRO-FILHO, N. P.; DA SILVA, J. A. Visual perception of extent and the geometry of visual space. Vision Research, v. 44, n. 2, p. 147-156, 2004.

FOUND, A.; MÜLLER, H. J. Efficient search for size targets on a background texture gradient: Is detection guided by discontinuities in the retinal-size gradient of items? Perception, v. 30, n. 1, p. 21-48, 2001.

FUKUSIMA, S. S.; FERREIRA-BACCI, A. V.; ALVES, N. T. Gradiente de Perspectiva e interpretação da linha do horizonte amplificam tamanhos percebidos (resumo 04.033). In: Resumos, 20. Reunião Anual da FeSBE, 2005, Águas de Lindóia, SP, 2005.

FUKUSIMA, S. S.; FAUBERT, J. Perceived length in the central visual field: evidence for visual field asymmetries. Vision Research, v. 41, p. 2119-2126, 2001.

GEISLER, W. S.; KERSTEN, D. Illusions, perception and bayes. Nature Neuroscience, v. 5, p. 508-510, 2002.

GESCHEIDER, G. A. Psychophysics: the fundamentals. Mahwah, New Jersey: LEA, 1997.

GIBSON, E. J. The development of perception as an adaptive process. American Scientist, v. 58, p. 98-107, 1970.

GIBSON, J. J. The ecological approach to visual perception. Boston: Houghton Mifflin, 1979.

GILCHRIST, J. M.; JERWOOD, D.; ISMAIEL, H. S. Comparing and unifying slopes estimates across psychometric function models. Perception \& Psychophysics, v. 67, n. 7, p. 1289-1303, 2005.

GOODENOUGH, B.; GILLIAM, B. Gradients as visual primitives. Journal of Experimental Psychology: Human Perception and Performance, v. 23, n. 2, p. 370-387, 1997.

GULICK, W. L.; STAKE, R. E. The effect of time on size-constancy. The American Journal of Psychology, v. 70, n. 2, p. 276-279, 1957.

HABER, R. N.; LEVIN, C. A. The independence of size perception and distance perception. Perception \& Psychophysics, v. 63, n. 7, p. 1140-1152, 2001.

HAIR, J. F. et al. Análise Multivariada de Dados. 5 ed., Porto Alegre: Bookman, 2005. 
HARWERTH, R. S.; MOELLER, M. C.; WENSVEEN, J. M. The effects of cue context on the perception of depth from combined disparity and perspective cues. Optometry and Vision Science, v. 75, p. 433-444, 1998.

HE, Z. J.; NAKAYAMA, K. Visual attention to surfaces in 3-D space. Proceedings of the National Academy of Sciences of the USA, v. 92, p. 11155 - 11159, 1995.

HILLIS, J. M. et al. Slant from texture and disparity cues: Optimal cue combination. Journal of Vision, v. 4, n. 12, p. 967-992, 2004.

HOFFMAN, J. E.; SUBRAMANIAM, B. The role of visual attention in saccadic eye movements. Perception \& Psychophysics, v. 57, n. 6, p. 787-795, 1995.

HOLWAY, A. H.; BORING, E. G. Determinants of apparent visual size with distance variant. American Journal of Psychology, v. 54, p. 21-37, 1941.

IMAMURA, M.; NAKAMIZO, S. Evidence for the formal equivalence between Emmert's law and size-distance invariance hypothesis. Vision, v. 17, n. 4, p. 237-241, 2005.

IMURA, T.; TOMONAGA, M. Visual search on the ground-like surface defined by texture gradients in chimpanzees (Pan troglodytes) and humans (Homo sapiens) (Abstract). Journal of Vision, v. 7, n. 9, p. 284, 2007.

JACOBS, R. A. What determines visual cue reliability. Trends in Cognitive Science, v. 6, p. 345-350, 2002.

JACOBS, R. A. Optimal integration of texture and motion cues to depth. Vision Reserarch, v. 39, p. 3621-3629, 1999.

JUAN, C. H. et al. Segregation of visual selection and saccades in human frontal eye fields. Cerebral Cortex Advance Access. Disponível em: <www.cercor.oxfordjournals.org>, 2008

JUAN, C. H.; SHORTER-JACOBI, S. M.; SCHALL, J. D. Dissociation of spatial attention and saccade preparation. Proceedings of the National Academy of Sciences of the USA, v. 101, n. 43, p. 15541-15544, 2004.

KAUFMAN, L.et al. Perceptual distance and the moon illusion. Spatial vision, v. 20, n. 1-2, p. 155-175, 2007.

KING-SMITH, P. E.; ROSE, D. Principles of an adaptative method for measuring the slope of the psychometric function. Vision research, v. 37, n. 12, p. 1595-1604, 1997.

KNILL, D. C.; SAUNDERS, J. A. Do humans optimally integrate stereo and texture information for judgments of surface slant? Vision Research, v. 43, p. 2539-2558, 2003.

LANDY, M. S. et al. Measurement and modeling of depth cue combination: in defense of weak fusion. Vision Research, v. 35, p. 389-412, 1995. 
LAPPIN, J. S.; SHELTON, A. L.; RIESER, J. J. Environmental context influences visually perceived distance. Perception \& Psychophysics, v. 68, n. 4, p. 571-581, 2006.

LEVINSON, M.; RESTLE, F. Invalid results from the method of constant stimuli. Perception \& Psychophysics, v. 4, p. 121-122, 1968.

LIU T.; HEEGER D. J.; CARRASCO M. Neural correlates of the visual vertical meridian asymmetry. Journal of Vision, v. 6, n. 11, p. 1294-306, 2006.

LOOMIS J. M.; PHILBECK J. W.; ZAHORIK, P. Dissociation between location and shape in visual space. Journal of Experimental Psychology: Human Perception and Performance, v. 28, p. 1202-1212, 2002.

MACEVOY, S. P.; FITZPATRICK, D. Visual physiology: perceived size looms large. Current Biology, v. 16, n. 9, p. 330-332, 2006.

MASCHKE, M. et al. Depth perception in cerebellar and basal ganglia disease. Experimental Brain Research, v. 175, n. 1, p. 165-176, 2006.

MASIN, S. C. Different biases in the methods of constant and single stimuli. Bulletin of the Psychonomic Society, v. 25, p. 379-382, 1987.

MASIN, S. C.; VIDOTTO, G. A review of the formulas for the standard error of a threshold from the method of constant stimuli. Perception \& Psychophysics, v. 31, p. 585-588, 1982.

MON-WILLIAMS, M.; TRESILIAN, J. R. The size-distance paradox is a cognitive phenomenon. Experimental Brain Research, v. 126, n. 4, p. 578-582, 1999.

MORITA, H.; KUMADA, T. Effects of pictorially-defined surfaces on visual search. Vision Research, n. 43, p. 1869-1877, 2003.

MURRAY, S.O.; BOYACI, H.; KERSTEN, D. The representation of perceived angular size in human primary visual cortex. Nature Neuroscience, v. 9, p. 429-434, 2006.

NACHMIAS, J. The role of virtual standards in visual discrimination. Vision Research, v. 46, n. 15, p. 2456-2464, 2006.

NAKAYAMA, K.; MACKEBEN, M. Sustained and transient components of focal visual attention. Vision Research, v. 29, p. 1631-1646, 1989.

NEGGERS et al. TMS pulses on the frontal eye fields break coupling between visuospatial attention and eye movements. Journal of Neurophysiology, v. 98, p. 2765-2778, 2007.

O'BRIEN J.; JOHNSTON, A. When texture takes precedence over motion in depth perception. Perception, v. 29, n. 4, p. 437-52, 2000. 
ONO, F.; KAWAHARA, J.-I. Subjective area size influences time perception (Abstract). Journal of Vision, v. 7, n. 9, p. 383, 2007.

ORUÇ, I.; MALONEY, L. T.; LANDY, M. S. Weighted linear cue combination with possibly correlated error. Vision Research, v. 43, p. 2451-2468, 2003.

OZKAN, K.; BRAUNSTEIN, M. L. Background surface and horizon effects in the perception of relative size (Abstract). Journal of Vision, v. 6, n. 6, p. 421, 2006.

OZKAN, K.; BRAUNSTEIN, M. The position of objects relative to the horizon affects sizedistance invariance (Abstract). Journal of Vision, v. 7, n. 9, p. 286, 2007.

PARKS, N. A. Attending to pictorial depth: electrophysiological and behavioral evidence of visuospatial attention in apparent depth. Thesis for Master Degree, Georgia Institute of Technology, Atlanta, 2005.

POOM, L.; BÖRJESSON, E. Perceptual depth synthesis in the visual system as revealed by selective adaptation. Journal of Experimental Psychology: Human Perception and Performance, v. 25, p. 1-14, 1999.

PREVIC, F. H. Functional specialization in the lower and upper visual fields in humans: Its ecological origins and neurophysiological implications. Behavioral and Brain Sciences, v. 13, p. 519-565, 1990.

ROGERS, S. The horizon-ratio relation as information for relative size in pictures. Perception \& Psychophysics, v. 58, n. 1, p. 142-152, 1996.

SAKATA, H.; TSUTSUI, K.; TAIRA, M. (2005). Toward an understanding of the neural processing for 3D shape perception. Neuropsychologia, v. 43, n. 2, p. 151-161, 1996.

SAUNDERS, J. A.; BACKUS, B. T. Perception of surface slant from oriented textures. Journal of Vision, v. 6, n. 9, p. 882-897, 2006.

SANTOS, N. A.; SIMAS, M. L. B. Função de Sensibilidade ao Contraste: Indicador da Percepção Visual da Forma e da Resolução Espacial. Psicologia: Reflexão e Crítica, v. 14, n. 3, p. 589-597, 2001.

SCHIFFMAN, H. R. Sensação e Percepção. Rio de Janeiro: LTC, 2005.

SEDGWICK, H. A. The geometry of spatial layout in pictorical representation. In: M. A. Hagen, The Perception of Pictures (Vol.1, 33-90). New York: Academic Press, 1980.

SIMPSON, W. A. The method of constant stimuli is efficient. Perception \& Psychophysics, v. 44, p. 433-436, 1988. 
SINAI, M. J.; OOI T. L.; HE, Z. J. Terrain influences the accurate judgement of distance. Nature, v. 395, n. 6701, p. 497-500, 1998.

STERnBERG, R. J. Psicologia Cognitiva. Porto Alegre: Artes Médicas, 2000.

STEVENS, K. A. On gradients and texture "gradients". Journal of Experimental Psychology: General, v. 113, n. 2, p. 217-220, 1984.

TALGAR, C. P.; CARRASCO, M. Vertical meridian asymmetry in spatial resolution: visual and attentional factors. Psychonomic Bulletin \& Review, v. 9, n. 4, p. 714-22, 2002.

TONG, F. Primary visual córtex and visual awareness. Nature Review: Neuroscience, v. 4, p. 219-229, 2003.

TOZAWA, J.; OYAMA, T. Effects of motion parallax and perspective cues on perceived size and distance. Perception, v. 35, n. 8, p. 1007 - 1023, 2006.

TREISMAN, A.; GORMICAN, S. Feature analysis in early vision: evidence from search asymmetries. Psychological Review, v. 95, p. 15-48, 1988.

TSUTSUI, K-I. et al. Integration of perspective and disparity cues in surface-orientationselective neurons of área CIP. Journal of Neurophysiology, v. 86, p. 2856-2867, 2001.

TSUTSUI, K.-I.; SAKATA, H.; NAGANUMA, T. Neural correlates for perception of 3D surface orientation from texture gradient. Science, v. 298, p. 409-412, 2002.

TSUTSUI, K.; TAIRA, M.; SAKATA, H. Neural mechanisms of three-dimensional vision. Neuroscience Research, v. 51, n. 3, p. 221-229, 2005.

VAN DER LUBBE et al. Spatiotemporal overlap between brain activation related to saccade preparation and attentional orienting. Brain Research, v. 1072, p. 133-152, 2006.

WATSON, A. B.; FITZHUGH, A. The method of constant stimuli is inefficient. Perception \& Psychophysics, v. 47, v. 1, p. 87-91, 1990.

WELCHMAN, A. E et al. 3D shape perception from combined depth cues in human visual córtex. Nature Neuroscience, v. 8, p. 820 - 827, 2005.

WILLIAM, P. A.; ENNS, J. T. Pictorial depth and framing have independent effects on the horizontal-vertical illusion. Perception, v. 25, n. 8, p. 921- 926, 1996.

WRAGA, M. The role of eye height in perceiving affordances and object dimensions. Perception \& Psychophysics, v. 61, n. 3, p. 490-507, 1999.

WU, B.; HE, Z. J.; OOI, T. L. The linear perspective information in ground surface representation and distance judgment. Perception \& Psychophysics, v. 69, n. 5, p. 654-672, 2007. 
YOUNG, M. J.; LANDY, M. S.; MALONEY, L. T. A perturbation analysis of depth perception from combinations of texture and motion cues. Vision Research, v. 33, p. 26852696, 1993.

XUAN, B. et al. Larger stimuli are judged to last longer. Journal of Vision, v. 7, n. 10, p. 1-5, 2007. 
6 ANEXOS 
ANEXO A - Termo de Consentimento Livre e Esclarecido

Esta pesquisa tem por objetivo investigar como informações de profundidade afetam o desempenho em se comparar visualmente o tamanho de barras.

O requisito para que você participe desta pesquisa é ter boa acuidade visual. Por isso, antes de realizar o experimento você deverá submeter-se a um teste de acuidade visual.

Caso você preencha esse requisito e queira participar como voluntário desta pesquisa sua tarefa será a seguinte: indicar dentre duas barras, qual é a maior. As barras serão apresentadas num monitor de computador e suas respostas serão coletadas através do teclado do mesmo.

O experimento não apresenta riscos à integridade de sua saúde física ou mental e terá uma duração de aproximadamente 40 minutos.

É importante que você finalize o experimento, porém, se desejar interrompê-lo ou encerrá-lo, você assim poderá proceder a qualquer momento, sem qualquer prejuízo a você.

Os dados desta pesquisa serão divulgados em reuniões e publicações científicas e as identidades dos participantes serão mantidas em absoluto sigilo.

Declaro que estou ciente das informações acima e concordo em participar da pesquisa.

Local e data:

Nome do participante:

Endereço:

Assinatura do participante:

Nome do Pesquisador: Leonardo Gomes Bernardino

Assinatura do pesquisador:

Orientador: Prof. Dr. Sérgio Sheiji Fukusima

Assinatura do orientador:

Endereço: Av. Bandeirantes, 3900. Bairro: Monte Alegre. Cep: 14.040-901. Ribeirão Preto-SP

Universidade de São Paulo - Faculdade de Filosofia, Ciências e Letras.

Departamento de Psicologia e Educação. Telefone: (16) 3602-3729/3602-4448 
ANEXO B - Parecer do Comitê de Ética em pesquisa da FFCLRP-USP

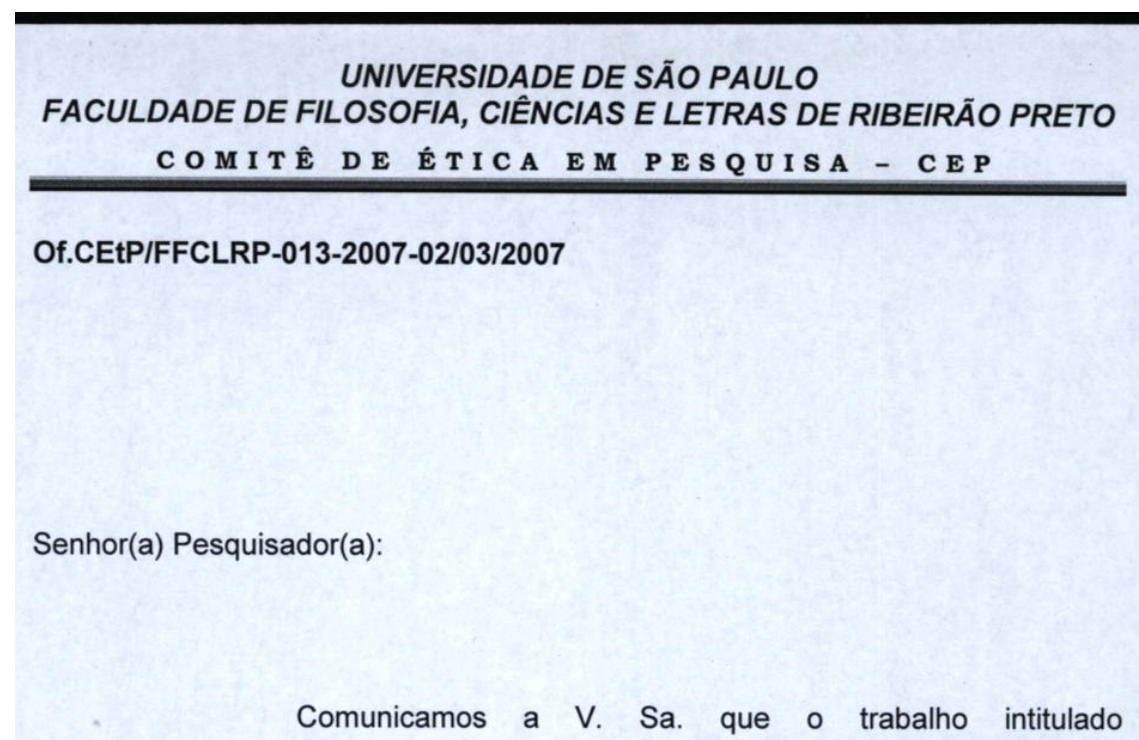
"COMPARAÇÕES DE TAMANHOS SOB INFORMAÇÕES PICTÓRICAS DE PROFUNDIDADE PROVENIENTES DE GRADIENTES DE TEXTURA E HORIZONTE EM EXPOSIÇÕES BREVES", foi analisado pelo Comitê de Ética em Pesquisa da FFCLRP-USP em sua $58^{a}$ reunião ordinária realizada em 1/3/2007, e enquadrado na categoria: APROVADO, de acordo com o Processo CEP-FFCLRP n³00/2006 - 2006.1.1936.59.7.

Aproveitamos a oportunidade para apresentar nossos protestos de estima e consideração.

Atenciosamente,

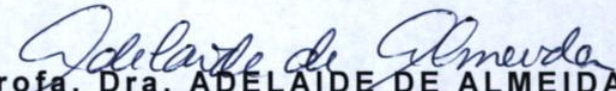

Profa. Dra ADELAIDE DE ALMEIDA

Coordenadora do Comitê de Ética em Pesquisa - FFCLRP-USP

Ilustríssimo(a) Senhor(a)

LEONARDO GOMES BERNARDINO

Aluno do Programa de Pós-Graduação em Psicobiologia desta FFCLRP-USP

c.c: Prof. Dr. SÉRGIO SHEIJI FUKUSIMA - Orientador

CEP-FFCLRP-USP - Fone: (016) 602-3653 - Fax: (016) 633-5015 Avenida Bandeirantes, 3900 - Bloco A - 14040-901 - Ribeirão Preto - SP - Brasil 